\title{
Enantioselective Synthesis of $\beta$-amino acids: A Review
}

\author{
Muhammad Ashfaq $^{1 *}$, RukhsanaTabassum ${ }^{1}$, Muhammad Mahboob Ahmad ${ }^{2}$, Nagina Ali Hassan ${ }^{1}$, Hiroyuki Oku ${ }^{3}$ and Gildardo Rivera ${ }^{4}$ \\ ${ }^{1}$ Department of Chemistry, The Islamia University of Bahawalpur, Bahawalpur, Pakistan \\ ${ }^{2}$ Institute of Chemical Sciences, Bahauddin Zakariya University, Multan, Pakistan \\ ${ }^{3}$ Department of Chemistry \& Chemical Biology, Gunma University Kiryu, Gunma 376-8515, Japan \\ ${ }^{4}$ Centro de Biotecnología, Genómica, Instituto Politécnico Nacional, 88710, Reynosa, México
}

\begin{abstract}
The synthesis of enantioselective $\beta$-amino acids is being reported in this review on account of their significant properties as proteinogenic, non-proteinogenic role such as neurotransmitter, biosynthesizer and nutritional supplementing materials etc. They are extensively used as chiral starting materials, auxiliaries and catalysts in organic synthesis. According to literature evidences, extensive research has been carried out to develop the methodologies for the synthesis of stereoselective $\beta$-amino acids. In this review, we describe recent advances in synthetic routes of enantioselective $\beta$-amino acids derivatives with chemical reactions during the last decades and to provide the most suitable route of their synthesis to compete the future challenges.
\end{abstract}

Keywords: $\beta$-amino acids; Enantioselective; Synthesis

\section{Introduction}

Enantionselective synthesis of $\beta$-amino acids has gained significant importance because of their interesting pharmacological applications as hypoglycaemic and antiketogenic properties, antibacterial and antifungal activities, antihelminthic as well potent insecticidal properties activities [1-3]. $\beta$-amino acids are fundamental building blocks for the preparation of pharmaceutical and agrochemical target molecules. They have displayed a high tendency towards the formation of $\beta$-peptides stable secondary structures (turns, sheets, and helices) and they are extensively used as chiral starting materials, auxiliaries and catalysts in organic synthesis [4-6]. Ennantioselectively defined $\beta$-amino acids are applied in drug development, molecular recognition, bimolecular structure and functional studies [3-7]. However, the synthesis of $\beta$-amino acids bearing various functional groups on the $\beta$-carbon with thiadiazole ring systems have been well studied due to having variety of biological activities, including antifungal, antitubercular, antibacterial, anticancer, and analgesic properties $[8,9]$.

Different methodologies have been tried out for their synthesis to maintain desired chirality is a big challenge. Several different catalytic asymmetric approaches to synthesize $\beta$-amino acids involving carboncarbon, carbon-nitrogen, and carbon-hydrogen bond forming reactions have been developed [10]. As per literature evidences, the enantioslective derivative of $\beta$-amino acid like $N$-acyl- $\beta$-(amino) acrylates was prepared by using $\mathrm{Ru}\left(\mathrm{O}_{2} \mathrm{CCH}_{3}\right)_{2}$ as catalyst [1]. Similarly $\mathrm{Ru}$ and $\mathrm{Rh}$ chiral mono- and bi-dentate phosphorous homogeneous catalysts were used for their synthesis through hydrogenation standard procedure. The hydrogenation of $(Z)$-enamines catalysed by bisphosphepine ligand was proceeded by Zhang et al. (Scheme 1) with $90 \%$ high yield. On the contrary, using the same catalyst system, $(E)$ enamines give only low yield [11].

High enantioselectivity in Rh-catalyzed hydrogenations can also be obtained by phosphite and other phosphorous ligands [12]. When phthalimide protected acrylates are hydrogenated using carbohydratephosphite $\beta^{2}$ - amino acid derivatives are formed with $99 \%$ yield (Scheme 2) [13].
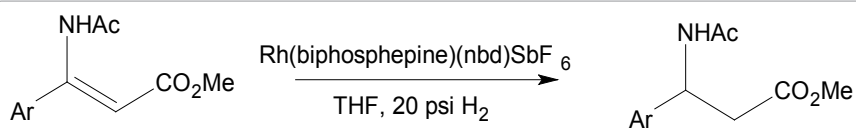

Scheme 1: Rhodium-bis phosphepine catalyzed hydrogenation of (Z)enamines.
Phosphoramidite ligand was used to obtain adducts in high yields with up to $94 \%$ by Fillion et al. through conjugate addition of dialkylzinc reagents to 2-aryl acrylate (Scheme 3). Deprotection of adduct, followed by a Curtius rearrangement of the succinic acid derivative resulted in the formation of $\beta$-amino acid derivative [14].

Sibi et al. reported an enantioselective rhodium catalysed enolate protonation method for the synthesis of $\beta^{2}$-amino acid (Scheme 4). $\mathrm{Rh}$ (acac)(ethylene) ${ }_{2}$ and difluorophos used to form a complex which catalyzed the conjugate addition of aryl boronic acids to $\beta$-acrylates. The intermediate oxa- $\beta$-allyl-Rh resulted in good yields using one equivalent of phthalimideas proton source [15].

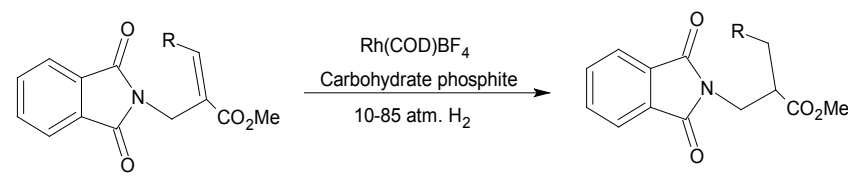

Scheme 2: Rh-catalyzed hydrogenation of phthalimide protected acrylates.

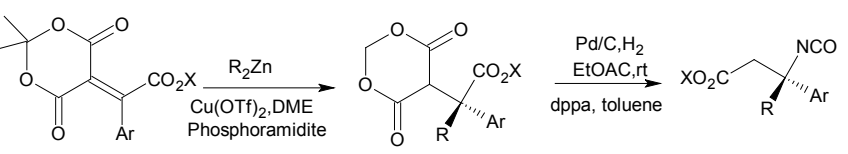

Scheme 3: Cu-catalyzed dialkylzinc to 2-aryl-acrylates to form quaternary stereo centers.

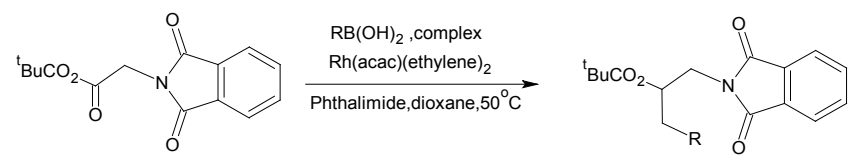

Scheme 4: Enantioselective rhodium catalyzed conjugate addition and protonation.

${ }^{*}$ Corresponding author: Muhammad Ashfaq, Department of Chemistry, The Islamia University of Bahawalpur, Bahawalpur, Pakistan, Tel: +92 3006829307 +92 62 9255473; Fax: +92 62 9255563, E-mail: chashfaqiub@yahoo.com

Received May 05, 2015; Accepted July 15, 2015; Published July 27, 2015

Citation: Ashfaq M, Tabassum R, Ahmad MM, Hassan NA, Oku H, et al. (2015) Enantioselective Synthesis of $\beta$-amino acids: A Review. Med chem 5: 295-309. doi: 10.4172/2161-0444.1000278

Copyright: $\odot 2015$ Ashfaq M, et al. This is an open-access article distributed under the terms of the Creative Commons Attribution License, which permits unrestricted use, distribution, and reproduction in any medium, provided the original author and source are credited. 
A dipeptide antibiotic TAN-1057 A,B was synthesized (58\% yield) via tri-N-Cbz-L-arginine and diazoketone in 1:1 molar ratio while the tert-butyl alcohol/water is used as solvent. The overall chemical reaction is given in Scheme 5 [16].

On the other hand enantioselective $\beta$-amino acids were synthesized in good yield from $\mathrm{N}$-protected amino acids via reduction of carboxyl function, $\beta$-amino alcohol into corresponding $\beta$-amino iodide and cyanides (Scheme 6) [17].

The conjugate addition of cyanide to $\alpha, \beta$-unsaturated imides using aluminium-salen catalyst was reported by Jacobsen et al. (Scheme 7). The basic hydrolysis of the imide to the corresponding carboxylic acid resulted in the formation of adducts which were transformed into $\beta$-amino acids, under acidic conditions the $\beta$-amino acids are converted to corresponding carboxylic acid followed by Curtius rearrangement with diphenylphosphorylazide (dppa) and hydrolysis of the nitrile group [18].

2,2'-bis(diphenylphosphino)-1,1'-binaphtyl (BINAP) in its dimeric form used to derive cationic catalyst which was employed by Sodeoka et al. in the synthesis of $\beta$-amino acids. The adducts in high

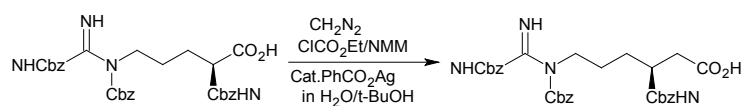

$$
\begin{aligned}
& \text { (A) } \\
& \text { (A) } \longrightarrow
\end{aligned}
$$

Scheme 5: Arndt-Eistert reaction in the total synthesis of TAN-1057A, and TAN-1057B.

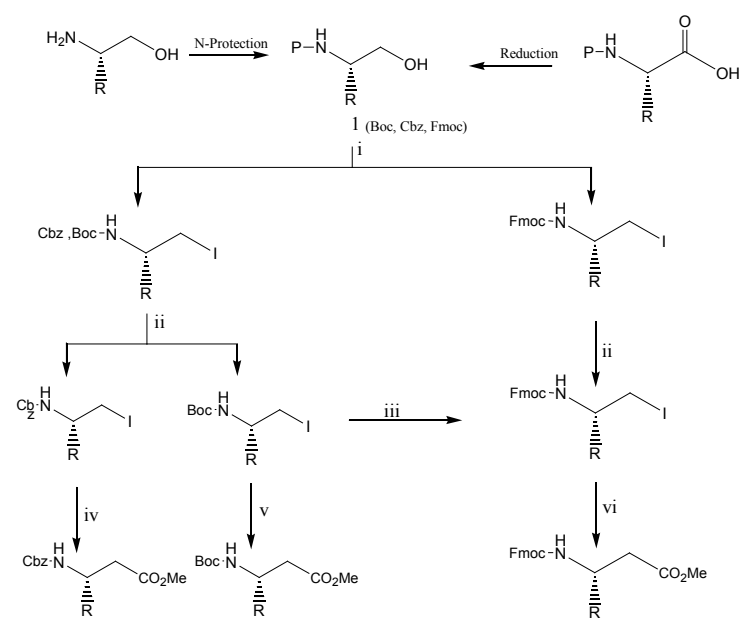

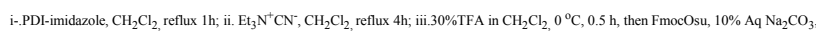
THF, room temp. $1 \mathrm{~h}$; ivexcess con, $\mathrm{HCl} / \mathrm{MeOH}, \mathrm{Et}_{2} \mathrm{O}, 4^{\circ} \mathrm{C} 12 \mathrm{~h}$; vas iv without $\mathrm{Et}_{2} \mathrm{O}$, room temp. $12 \mathrm{~h}$; vi. excess con. aq $\mathrm{HCl}$, dioxane, reflux 8

Scheme 6: Synthesis of $\beta$-amino acid by reduction of $N$-protected $\alpha$-amino acid.

$$
\text { PrOH, Toluene }
$$

Scheme 7: Aluminium-salen catalyzed addition of cyanide to $\alpha-\beta$ unsaturated imides. yield are obtained from aromatic amines substituted with electron donating or withdrawing groups (Scheme 8) [19].

In 2007, a diphenylamine-tethered bisoxazoline Zn(II) complex was used to add methoxyfuran to aromatic nitro olefins in an asymmetric Friedel-Crafts alkylation of 2-methoxyfuran with nitroalkenes with yield upto $96 \%$ (Scheme 9). The furan ring oxidatively give an intermediate which is then treated with diazomethane to form the $\beta$-nitro ester from which the corresponding $\beta^{2}$-amino acids are obtained [20].

In the following scheme 10, Candida antarctica lipase A and B enzymes played a vital role in synthesis of enantiomeric ( $S$ and $R$ ) $\beta$-amino acids, because lipase can achieve resolution of a racemic substrate [21-23].

Another way to easy synthesis of $S$ and $R \beta$-amino acids were preparedand reported by Soloshonok et al. The N-phenylacetyland malonic acid was taken as reactants in the presence of ammonium acetate. Penicillin acylase enzyme in aqueous media used to produce enantiomers. The scheme 11 describes the key steps of their synthesis [24].<smiles>[R]C=CC(=O)N1CCOC1=O</smiles>
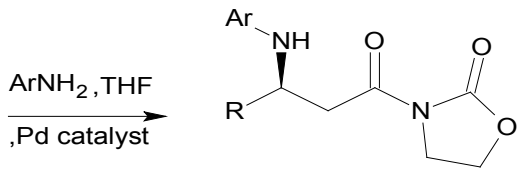

Scheme 8: Enantioselective aromatic amines to $\alpha-\beta$ unsaturated imides catalysed palladium.

$$
\text { (A) } \underset{\mathrm{CCl}_{4}, \mathrm{MeCN}_{2} \mathrm{H}_{2} \mathrm{O}}{\stackrel{\mathrm{RuCl}}{\mathrm{CH}_{2} \mathrm{~N}_{2}}} \underset{\mathrm{NaO}_{2} \mathrm{Me}}{\stackrel{\mathrm{Zn}(\mathrm{OTf})_{2} \text {, Xylene }}{\text { diphenylamine }}}
$$

Scheme 9: Zn-catalyzed Friedel-Crafts reaction of 2-methoxyfuran with nitroalkenes.

$$
\text { (A) Kanerva et al. }
$$

(B) Gotor et al.
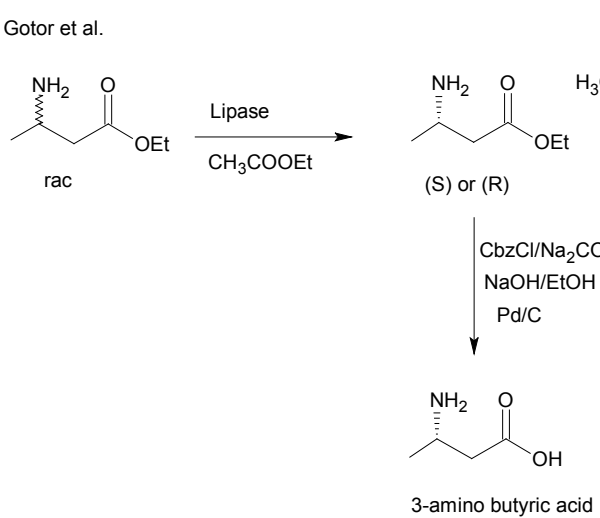

Scheme 10: Catalytic kinetic resolution of aliphatic $\beta$-substituted $\beta$-amino esters. 
A rhodium-catalyzed $\mathrm{C}-\mathrm{H}$ insertion of aromaticdiazoacetates into $N$-Boc- $N$-benzyl- $N$-methylamine was also used in the synthesis of $\beta^{2}$-amino acids (Scheme 12) [25]. Benzylaminewhich will give up to $96 \%$ yieldis used for insertion of various aromatic, heteroaromatic andalkenyldiazoacetates.

Aromatic $\beta^{3}$-aminoacid derivatives were obtained with up to $98 \%$ yield in the reaction ofsilylenol etherswith $\mathrm{N}$-BOC-aldimines having thiourea as a catalyst (Scheme 13) [26]. Comparable enantioselectivities were given by the catalyst i.e. thiourea due to variations in the amine part.

Amulti-step procedure for the synthesis of $\beta$-unsaturated $\beta^{2}$-amino acid derivatives was described by Walsh et al. (Scheme 14). First, enantioselectivevinylzinc addition to aldehydes yield allylic alcohol, followed by Overman's 3,3-sigmatropicimidate rearrangement by one-pot deprotection-oxidation sequence. The hydroboration of terminal alkyne with dicyclohexylborane and transmetalation of the vinylborane with diethylzinc generated vinylzinc reagents. The addition of the vinylzincreagent to aromatic and aliphatic aldehydes was catalyzed by ligands in high yield $99 \%$ using the trichloroacetonitrile in 1,8-diazabicyclo[5.4.0]undec-7-ene (DBU) to synthesize trichloroacetimidate and heated to reflux yielding the rearranged product. One-pot deprotection of the tritylalcohol and

$$
\underset{\mathrm{Cl}}{\mathrm{O}_{2}}
$$

Scheme 11: Condensation of aromatic aldehydes and malonic acid.

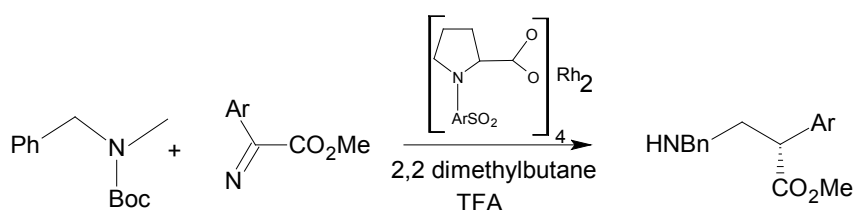

Scheme 12: Rh-catalyzed C-H-activation for the synthesis of $\beta^{2}$-amino acids.

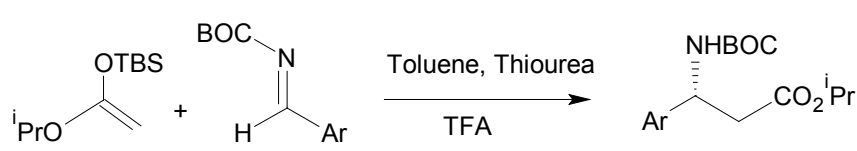

Scheme 13: Thiourea catalyzed asymmetric Mannich reaction.

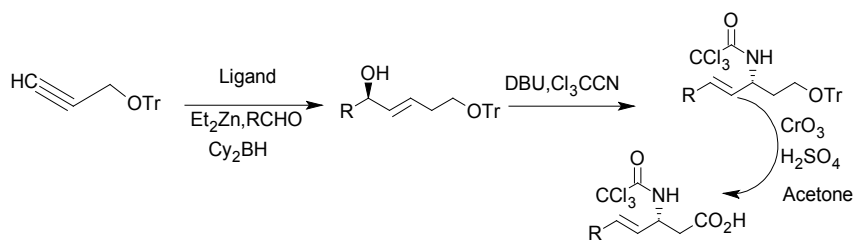

Scheme 14: Enantioselective addition of vinylzinc reagent for synthesis of $\beta$-amino acids. oxidation of the free hydroxyl group gave $N$-protected amino acid using chromium trioxide in sulphuric acid [27].

In another reaction, synthesis of N-BOC imines were catalysed by Cinchona alkaloid given in scheme 15 are moderate enantioselective amino acids [28].

Lavielle and co-workersused sultam- $\beta$-alaninate-derived Schiff base for the synthesis of $\alpha$-substituted $\beta$-amino acid derivatives. Lithium enolate was produced as a bi-product which is trapped with electrophiles. The reaction is given in scheme 16 [29].

The synthesis of protected aminotetroses and syn- $\beta$-hydroxy$\beta$-amino acids was successfully described by Córdova et al. using glycol aldehydes (Scheme 17a, b). They are enantioselective and diastereoselective in nature $[30,31]$.

Theprolinecatalysedaddition ofaldehydestoaromatic $N$-BOC-protected imines gave syn-adduct (Scheme 18) with excellent diastereoselectivities and enantioselectivities. This was reported by List et al. [32].

Cinchona alkaloid

Scheme 15: Cinchona alkaloid catalyzed asymmetric Mannich reaction.<smiles>CC1CC2CC1CN(C(O)COC(=O)CCN)C2S(=O)(=O)O</smiles>

(A)<smiles>[R]C(CN=C([PH2+])c1ccccc1)C(=O)SS(=O)(=O)C1C2CC3CC(C2)N([R])C1C3</smiles>

Scheme 16: Synthesis of $\alpha$-substituted $\beta$-amino acid derivatives.

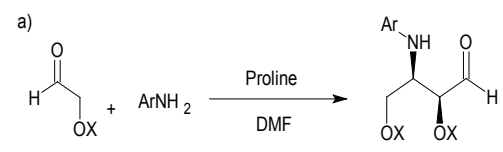

b)

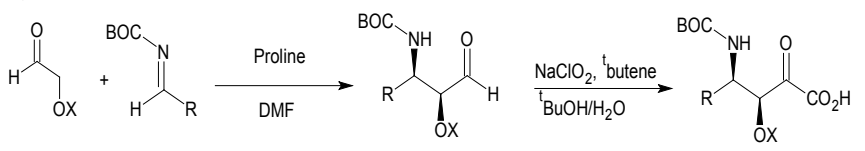

Scheme 17: Proline-catalyzed asymmetric synthesis of $\alpha$-hydroxy $\beta$ amino aldehydes.

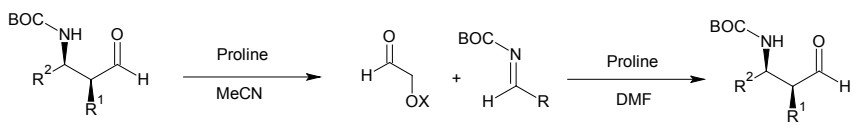

Scheme 18: Proline catalyzed asymmetric reaction of N-BOC-imines. 
The same group reported the proline catalyzed reaction of $\mathrm{N}$-BOCimines with acetaldehyde (Scheme19) [32].

Versatile asymmetric syn- $\alpha$-alkyl- $\beta$-amino esters may be generated in good yield and with excellent stereocontrol. Several examples illustrate these products may be debenzylated and hydrolysed to afford homo chiral syn- $\alpha$-alkyl- $\beta$-amino acids (Scheme 20) [33, 34].

In the following scheme 21 , Saito et al. produced isoxazolidinones which were converted to $\beta$-amino acids by reductive cleavage of the $\mathrm{N}-\mathrm{O}$ bond by double diastereo induction of chiral methyl benzylhydroxylamine to chiral esters [35].

Thiourea was used as a catalyst for the conjugate addition of $O$-substituted hydroxylamines to pyrazolecrotonates by Sibi et al. (Scheme 22). The yield of adducts is higher with aliphatic $\alpha$, $\beta$-unsaturated compounds as compared to the phenyl substituted substrates [36].

The synthesis of $\beta$-amino acids was also characterized by a new

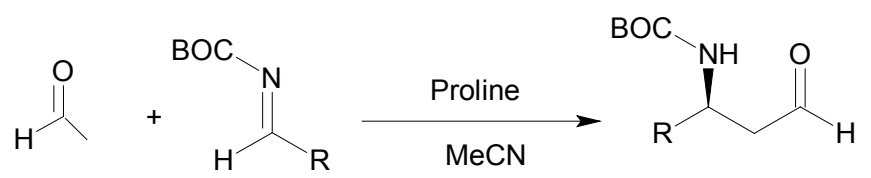

Scheme 19: Proline-catalyzed reaction of acetaldehyde.

$\underset{R^{2}}{\longrightarrow} \stackrel{O_{R}}{\longrightarrow}$

Scheme 20: Stereoselective $\beta$-amino acids synthesis.

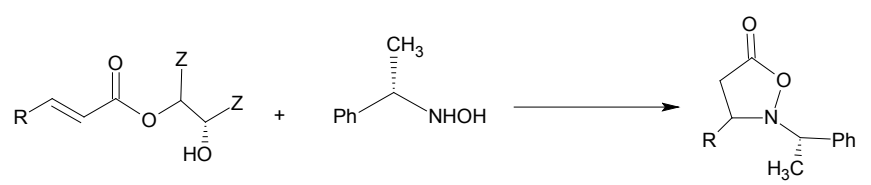

Scheme 21: Double diastereo induction to produce amino acids.

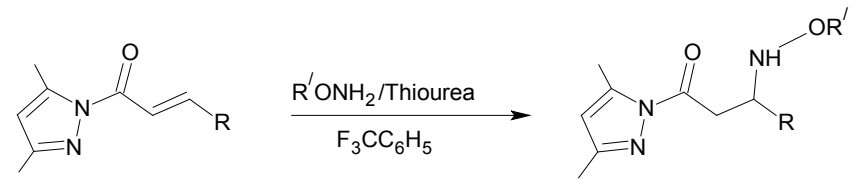

Scheme 22: Thiourea catalysed aza Michael addition of hydroxylamines.

$$
\begin{gathered}
\text { [Candida rugosa] } \\
\text { [Mesorhizobium sp. } \\
\text { transminase] }
\end{gathered}
$$

Scheme 23: Transaminase catalyzed synthesis of $\beta$-phenylalanine. biocatalyst which was named as $\beta$-transaminase (Scheme 23). The lipase from Candida rugosa catalyzes the hydrolysis of $\beta$-keto acid being the substrate for the transamination. The final product obtained was $\beta$-phenylalanine while the racemic $\beta$-alanine was used as nitrogen source [37].

Aromatic and heteroaromatic $\beta$-amino acids were employed to synthesize the corresponding $\beta$-amino acids. Phenylalanine amino mutase (PAM) has been used to synthesize $\beta$-Styryl- and $\beta$-aryl- $\beta$ alanine derivatives (Scheme 24) [38].

PAM was used by Janssen and Feringa et al. in a synthetic procedure for $\beta$-amino acids to catalyze the amination of cinnamic acid derivatives (Scheme 25). A mixture of $\alpha$ - and $\beta$-amino acids which remained unisolated or un-separated was obtained. By the substitution of electron donating groups in para-position of the aromatic ring corresponding $\beta$-amino acids are obtained [39].

$\beta$-amino acids were synthesized by transformation of enantioselective $\beta$-lactams. In this method, the di-substituted symmetric or asymmetric ketenes react with imines effectively to<smiles>[R]C[C@@H]([NH3+])C(=O)O[Na]</smiles>

Scheme 24: PAM catalyzed synthesis of $\beta$-amino acids from $\alpha$-amino acids.

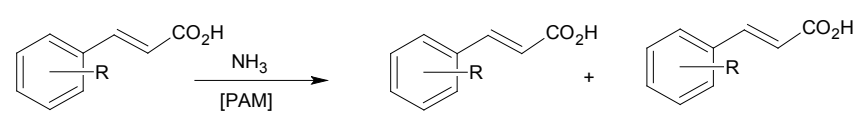

Scheme 25: PAM catalyzed synthesis of $\beta$-amino acids from cinnamic acid derivatives.

$$
\text { Heterocycle ligand }
$$

Scheme 26: Synthesis of $\beta$-amino acids by transformation of $\beta$-lactams

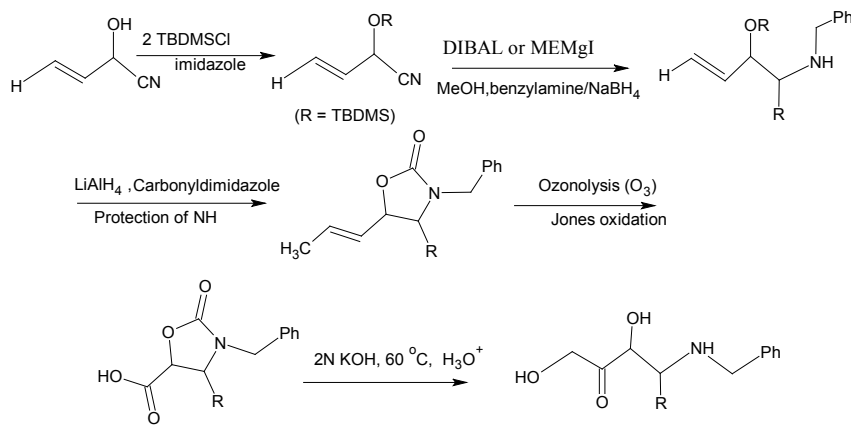

Scheme 27: Synthesis of N-benzoyl $\alpha$ - hydroxy $\beta$-amino acids. 
produce $\beta$-lactams which is preceded further to get enantioselective of high purity $\beta$ amino acids (Scheme 26) [40].

High enantiomeric and diastereomeric purity N-benzoyl $\alpha$ hydroxy $\beta$-amino acids was prepared by excellent chiral starting material cyanohydrin [(-)-(R,E)p-2-hydroxy-3-pentenenitrile] which was prepared by R-oxynitrilase catalytic addition of HCN to 2-butenal, reaction is described in the scheme 27 [41].

The use of chiralferrocenylphosphine ligand in the hydrogenation of ( $Z$ )-enamine esters with an unprotected amine group in trifluoroethanol (TFE) as solvent to yield the corresponding amino esters with excellent yield98\% (Scheme 28) [42].

MalPhoscatalyzed $(E)$-enamines with $99 \%$ yield and of the corresponding $(Z)$-enamines with $90 \%$ yield is reported (Scheme 29). In a similar reaction, Me-DuPhos gave also high yields with these $(E)$ enamines, but $(Z)$-enamines gave correspondingly lower yields [43].

The mixed ligand approach has been employed in the synthesis of $\beta$-amino acid catalyzed by rhodium-phosphoramidite complexes in order to further enhance the enantioselectivity. The combination of chiral phosphoramidite with achiral tris-o-tolyl-phosphine using the unprotected carboxylic acid was used for the synthesis of $\beta^{2}$-amino acids (Scheme 30) [44].

In 2005 , the addition of $\beta$-ketoesters to various imines catalyzed by a chiral cationic palladium complex was described by Sodeoka et al. (Scheme 31) [45]. The catalyzed addition of $\beta$ ketoesters to $\alpha$-imino esters gave the corresponding $\beta$-amino acids.

Shibasaki et al.in the direct asymmetric reaction of trichloromethyl ketones and pyridyl- orthienylsulfonyl-protected imines studied

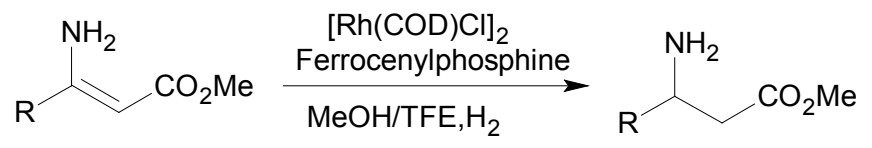

Scheme 28: Rhodium-ferrocenylphosphinecatalyzed hydrogenation of unprotected enamines.

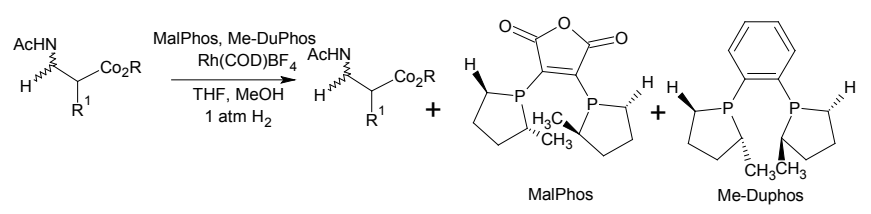

Scheme 29: Rhodium catalyzed hydrogenation of (E)- and (Z)-enamines.<smiles>[R]C=C(CNC(C)=O)C(=O)O</smiles>

$$
\begin{aligned}
& \text { Chiral phosphoramidite } \\
& \stackrel{\mathrm{Rh}(\mathrm{COD})_{2} \mathrm{BF}_{4}, \mathrm{p}(\mathrm{o} \text {-tol })_{3}}{\mathrm{CH}_{2} \mathrm{Cl}_{2}, 10 \text { bar } \mathrm{H}_{2}}
\end{aligned}
$$

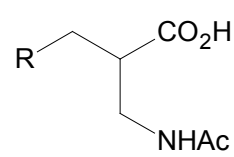

Scheme 30: Mixed ligand approach towards $\beta$-amino acids.

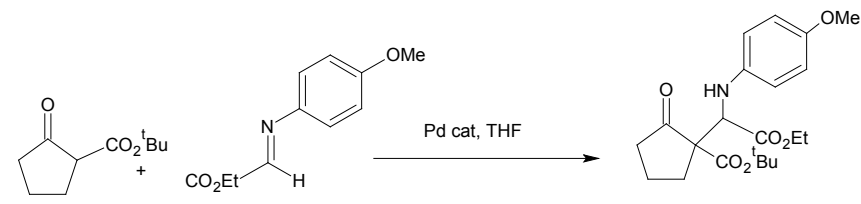

Scheme 31: Pd-catalyzed addition of $\beta$ keto esters to $\alpha$-imino esters.
La(III)- $i$ Pr-pybox (Scheme 32). The trend of the reaction was to use the aliphatic, aromatic and heteroaromatic imines as substrates. Using esterification the product was transformed into the $N$-BOC-protected $\beta^{2}$-amino ester under basic conditions [46].

Homonuclear $\mathrm{Ni}_{2}$-Schiff base complex was also reported by Shibasaki et al. for the synthesis of tetra substituted anti- $\alpha, \beta$-diamino acids (Scheme 33). The corresponding adducts were obtained with high yields from BOC-protected aromatic and aliphatic imines with nitroacetate. The nitro group was reduced to give $\alpha, \beta$-diamino ester using $\mathrm{NaBH}_{4} / \mathrm{NiCl}_{2}$, which was transformed to the corresponding acid [47].

Simple aromatic and enolizable aliphatic aldehydes, secondary amines and glycine derivatives are used as starting materials producing protected $\alpha, \beta$-diamino esters using Me-Duphos as ligand by Kobayashi (Scheme 34) [48].

Kobayashi et al. have also studied the asymmetric Mannichreaction (Scheme 35). The adducts with yield $84 \%$ are obtained by the reaction of $\beta$-dimethyl silylenol ethers with protected aromatic imines [49]

Feringa et al. obtained adducts of $\mathrm{Et}_{2} \mathrm{Zn}, \mathrm{Me}_{2} \mathrm{Zn}$ and $\mathrm{Bu}_{2} \mathrm{Zn}$ with high yield by the addition of dialkyl zinc reagents to acetal-substituted nitropropenoates (Scheme 36) [50]. Raney-Nickel reduction of the nitroalkane, followed by BOC-protection of the amine group and oxidation of the acetal under acidic conditions to the corresponding carboxylic acid gavethe corresponding $N$-BOC protected $\beta^{2}$-amino acids.

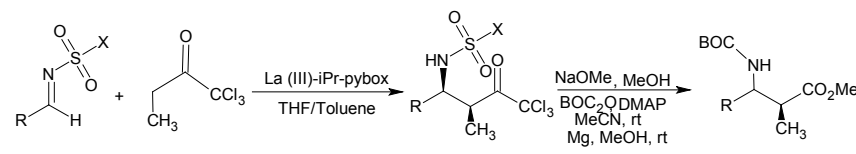

Scheme 32: La-catalyzed addition of trichloromethyl ketones to imines.

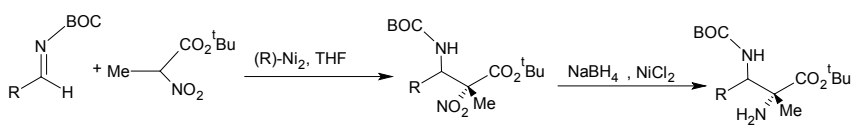

Scheme 33: Ni-catalyzed addition of nitroacetate to imines.

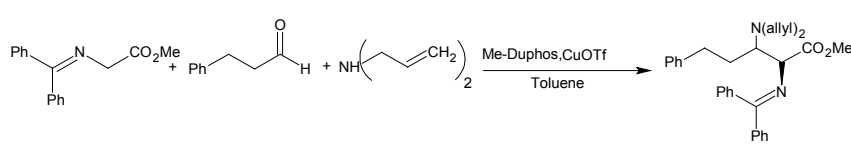

Scheme 34: Cu-catalyzed Mannich reaction of glycine derivative with aldehyde and amine.

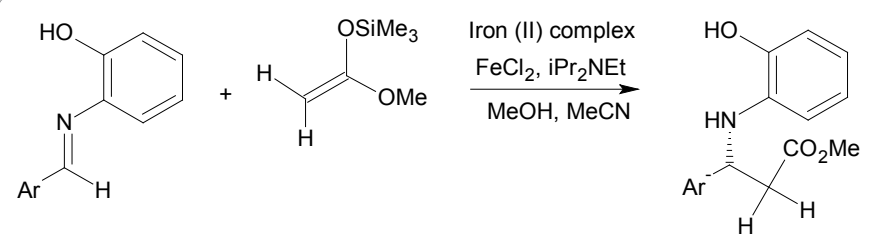

Scheme 35: Fe-catalyzed addition of silylenol ethers to aromatic imines.

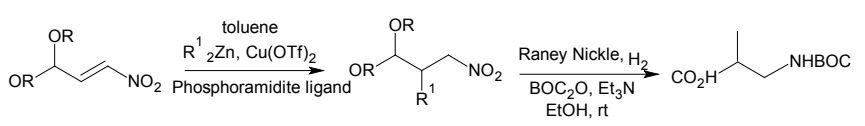

Scheme 36: Synthesis of $N$-BOC protected $\beta^{2}$-amino acids using $\mathrm{Cu}$ - and Raney Ni catalysts. 
Hii et al. investigated cationic palladiumbinap complex using aniline and crotonyloxazolidinone, to get enantioselective addition of primary aromatic amines to $\alpha, \beta$ unsaturated oxazolidinones (Scheme 37a) [51]. Similarly high yield 98\% obtained when cationic palladium complex was investigated in addition to aromaticamines to $\mathrm{N}$-alkenoylcarbamates (Scheme 37b) using various aliphatic substrates $(\mathrm{R}=\mathrm{Me}, \mathrm{Et}, \mathrm{Pr})$. By the hydrolysis of the imide under basic conditions, the products were converted to $N$-aryl- $\beta^{3}$-aminoacids [52].

The synthesis of $\beta^{2}$-amino acids was reported by Gellman et al. by the enantioselective aminomethylation of aldehydes (Scheme 38a). The $\beta$-amino aldehydes were reduced to the corresponding alcohols by reaction with Proline derivative. For the synthesis of $\beta^{2}$-amino acids, the amino alcohol was recrystallized as hydrochloride salt to increase the yield, the protecting groups removed by hydrogenation followed by BOC-protection, and the alcohol oxidized to the corresponding carboxylic acid [53, 54]. High yields up to $98 \%$ were obtained by Córdova et al. by using $\mathrm{LiBr}$ (Scheme $38 \mathrm{~b}$ ). The corresponding $\beta^{2}$-amino acid was synthesized by oxidation of the alcohol to the carboxylic acid after deprotection of the benzyl-protecting group re-protection using $\mathrm{BOC}_{2} \mathrm{O}[55]$.

A demonstration of the organocatalytic amine addition and the accompanying products is presented in the one pot conversion of simple aldehydes to enantio enriched $\beta$-amino acids. The 2 -hexenal reacts with asymmetric amination conditions followed by in situ Pinnick oxidation provided the corresponding $\beta$-amino acids with excellent enantioselective (92\%). N-O bond removal can be accomplished under mild reduced conditions ( $\mathrm{Zn} / \mathrm{AcOH})$ (Scheme 39) [56].

Similarly, in another report by Córdova et al. the $\alpha, \beta$-unsaturated aldehydes were obtained by the reaction of proline-derived chiral amine with $\mathrm{N}$-Cbz-methoxylamine as a nucleophile (Scheme 40a) [57]. The $\beta$-amino aldehydes obtained in high yield up to $99 \%$ undergo oxidation to the corresponding carboxylic acid and deprotection of the amine provided $\beta^{3}$-amino acids. When carbamate-protected hydroxylamines were used as nucleophile, the cyclic 5-hydroxy-isooxazolidinones were obtained with high yield up to $98 \%$ (Scheme $40 \mathrm{~b}$ ). The corresponding $\beta^{3}$

(a)<smiles>[R]C=CC(=O)N1CCOC1=O</smiles>

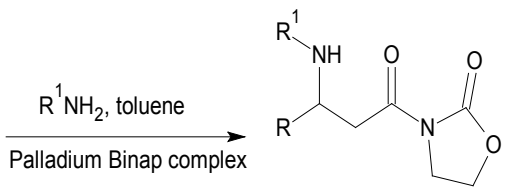

(b)

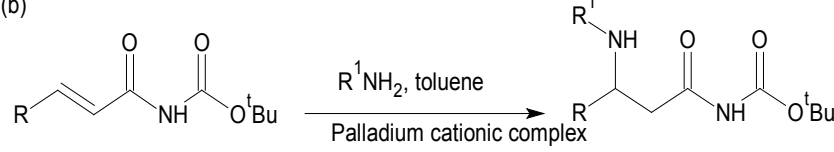

Scheme 37: Pd-catalyzed addition of aromatic amines to $\alpha-\beta$ unsaturated imides.

$$
\text { b) }
$$

Scheme 38: Synthesis of $\beta^{2}$-amino acids

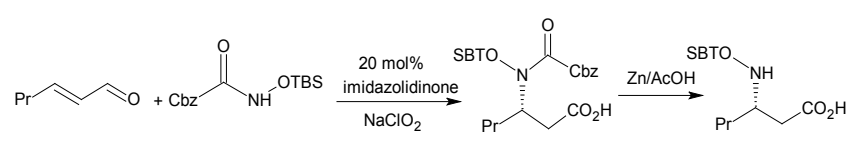

Scheme 39: Organo catalyticaza-Michael addition.

a)

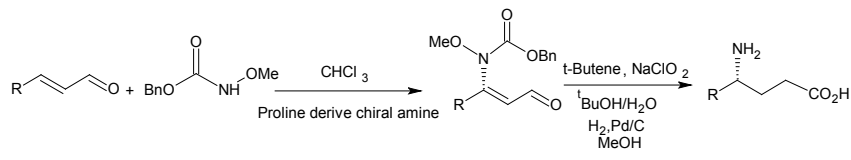

b)

Scheme 40: Organo catalytic aza Michael addition.

amino acids were obtained by subsequent cleavage by hydrogenolysis with high yield up to $97 \%$ [58].

The derivatives of $\beta$-amino acid were obtained with high yields through 1,3-asymmetric induction through radical mediated 1,5-hydrogen atom transfer and trapped by electrophilic olefins (Scheme 41) [59].

The preparation of syn- $\alpha$-hydroxy $\beta$-amino acids was reported in two steps by Cardillo and Gentilucci. The key stepof this synthesis was the formation of transoxazoline (Scheme 42).The PGA catalyzed kinetic resolution gave 3-amino-3-phenylpropanoic acid [60].

The enantioselective (R)-(+)- $\beta$-phenylalanine and (S)-(+)-ethyl$\beta$-amino-3-pyridinepropanoate have been prepared elsewhere in literature (Scheme 43). The reaction was completed by the addition of sodium enolate to chiral sulfinimine [61,62]. The sulfinyl group activated the carbon-nitrogen double bond, and therefore facilitates the additionof various nucleophiles. In similar methodology titanium enolate was added to tertbutanesulfinylimine by Ellman and Tang for the construction of $\beta, \beta$ disubstituted and $\alpha, \beta$ disubstituted $\beta$-amino acids [63].

In another approach $\alpha$-methyl- $\beta$-substituted $\beta$-amino esters were prepared by Badia et al., utilizing readily available (S, S)-(+)pseudoephedrine as chiral auxiliary (Scheme 44a) [64]. An asymmetric preparation of $\beta$-substituted $\beta$-aminoacids were explored by reactions of imines and chiral enolates (Scheme 44b) $[65,66]$.

TMS-SAMP as anucleophile was used by Enders et al. to synthesis $\mathrm{N}$-silylated $\beta$-hydrazino- estersin as aza analogous Michael addition process [67]. In a Tandem aza Michael addition intramolecular cyclization, the same reaction sequence was also applied to the synthesis of cyclic $\beta$-amino acids and heterocyclic $\beta$-amino acids [68]. Sibi et al. reported $\beta$-amino acid derivatives with $97 \%$ yield (Scheme 45 ) [69].

Lavielle et al. reported the asymmetric synthesis of the N-BOC protected derivative of (S)-3-Amino-2-phenyl propanoic acid featuring acylation of metallated phenylacetonitrile as the key step [70]. Another approach involved base catalyzed addition of (R)-pantolactone to $\mathrm{N}$-phthaloyl ketene following an entirely different strategy was later described by Calmes and Escale (Scheme 46) [71].

Prashad et al. reported the first enantioselective cyclic $\beta$-amino acid (+)-methylphenidate hydrochloride, which is a mild nervous system stimulant used for the treatment of attention deficit hyperactivity disorder (Scheme 47) [72, 73]. 


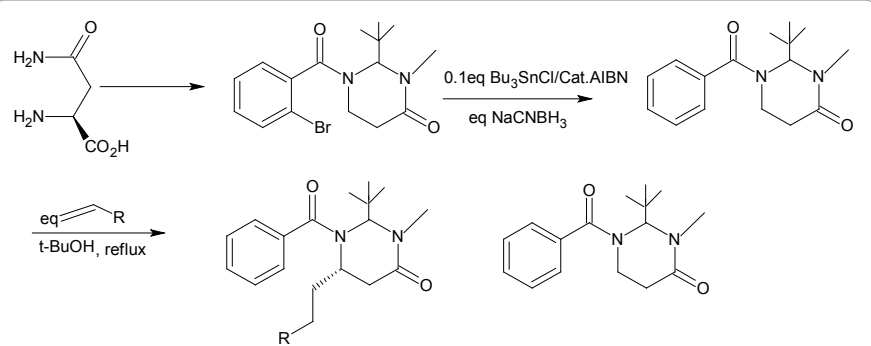

Scheme 41: Synthesis of $\beta$-amino acids derivatives through 1 , 3-asymmetric induction.

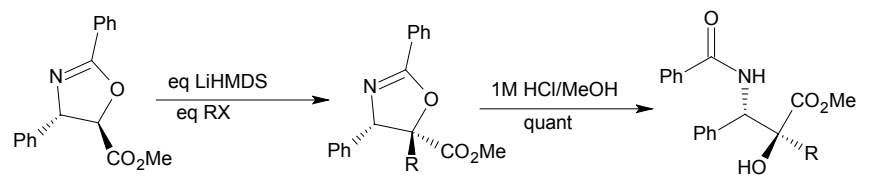

Scheme 42: Preparation of syn- $\alpha$-hydroxy $\beta$-amino acids.

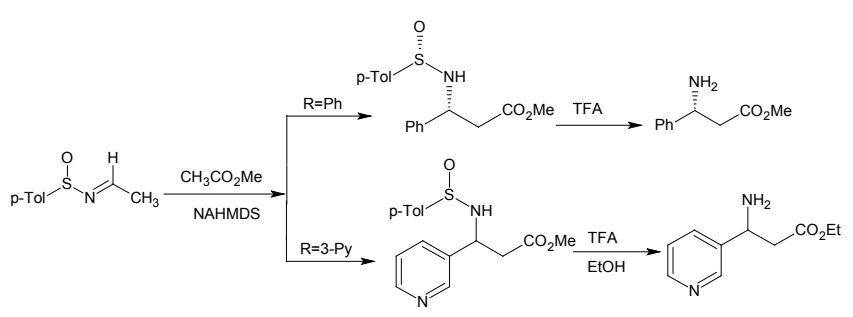

Scheme 43: The use of sulfoxides as chiral auxiliaries in asymmetric synthesis of $\beta$-amino acids.

a) Badia et al.

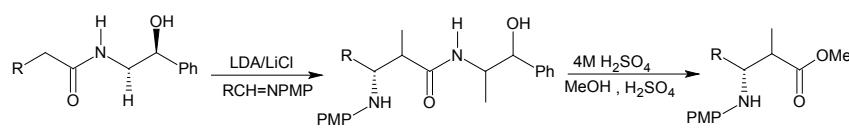

b) Zhao et al.

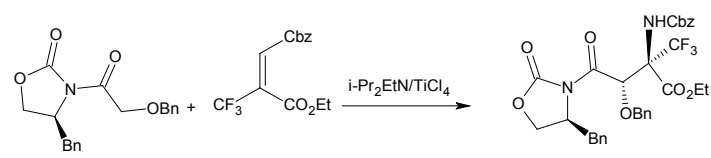

Scheme 44: Asymmetric preparation of $\beta$-substituted $\beta$-amino acids.

$$
\text { Where } \mathrm{Nu}=\mathrm{CH}_{\mathrm{R}}^{\mathrm{OTMS}}=\mathrm{CH}_{\mathrm{MeO}}^{\mathrm{OTM}, \mathrm{HFIP}, \mathrm{Cu}(\mathrm{OTf})_{2}}
$$

Scheme 45: Synthesis of $\beta$-amino acid derivatives.

$\mathrm{B}^{3}$-amino esters were obtained by Börner et al. using 1,3-diphenyl1,3-bis(diphenylphosphino) propanein the hydrogenation of (E)enamines (Scheme 48). The esters were then converted to the corresponding $\beta^{3}$-amino acids [74].

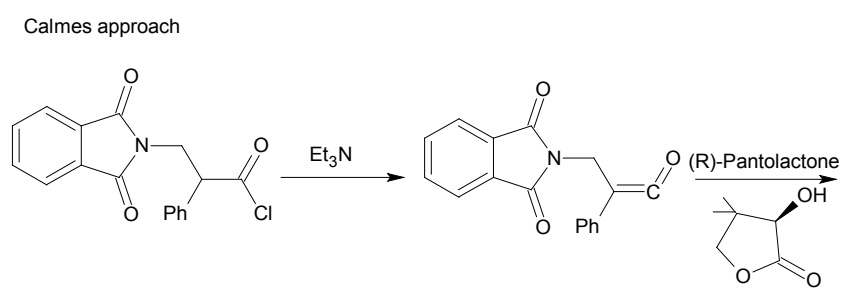<smiles>CC(=O)C(CN1C(=O)c2ccccc2C1=O)c1ccccc1</smiles>

Scheme 46: A base catalyzed addition of $\beta$-amino acids

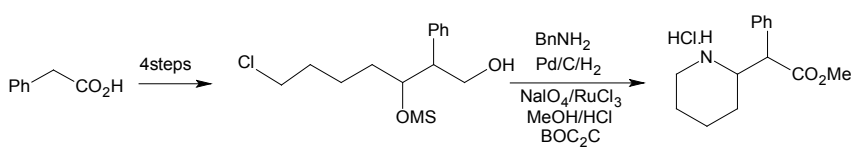

Scheme 47: Enantioselective synthesis of $\beta$-amino acid.

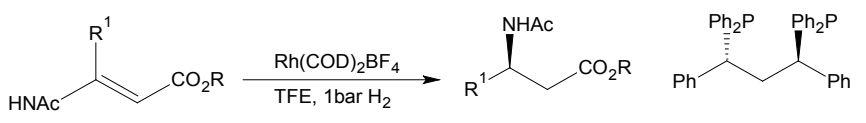

Scheme 48: Rhodium-diphenylphosphino-propane catalyzed hydrogenation of (E)-enamines.

Kim, Park and Beak recently synthesized $\beta$-phenyl amino acidsfrom $\mathrm{N}$-BOC-N-(p-methoxy- phenyl) benzylamine via (-)-sparteine/BuLi catalysed diastereoselective alkylation with substituted vinyl bromide, and subsequent oxidation with ozone, followed by Jones reagent (Scheme 49) [75].

Berkessel et al. studied thiourea catalyst for the kinetic resolution of racemic oxazinones (Scheme 50). The N-benzoyl- $\beta$-amino acid was isolated with $97 \%$ yield using hydrolytic environment [76].

The $a$-amino acid derived amide was reduced with imines with trichlorosilane which are in equilibrium with the corresponding enamines (Scheme 51). The $\beta$-amino esters obtained were converted to the corresponding $\beta$-aminoacids [77].

The polar solvents accelerate the hydrogenation of (Z)- $\beta$ aminoacrylate in the presence of Et-DuPHOS-Rh as a catalysts reported by Heller and co-workers. The corresponding $\beta$-amino acids were obtained from the $\mathrm{E}$ and $\mathrm{Z}$ isomers which were hydrogenated to give $\beta$-amino esters (Scheme 52) [78].

Various aminomutases have been used for the conversion of aliphatic and aromatic $\alpha$-amino acids to the corresponding $\beta$-isomers [39]. Various aromatic (S)- $\beta$ amino acids can be obtained by using phenylalanine aminomutase (PAM) in tandem with phenylalanine ammonialyase (PAL).The stereoselective hydrolysis of racemic phenyldihydrouracil to D- and L-N-carbamoyl- $\beta$-phenylalanine on further hydrolyse to corresponding $\beta$-amino acid [79].

Transaminases (also known as aminotransferases) possess a great potential for the synthesis of optically pure-amino acids [80]. Transaminases can be applied either for the kinetic resolution of racemic compounds or the asymmetric synthesis starting from a prochiral substrate. The catalytic ring-expansive carbonylation of 


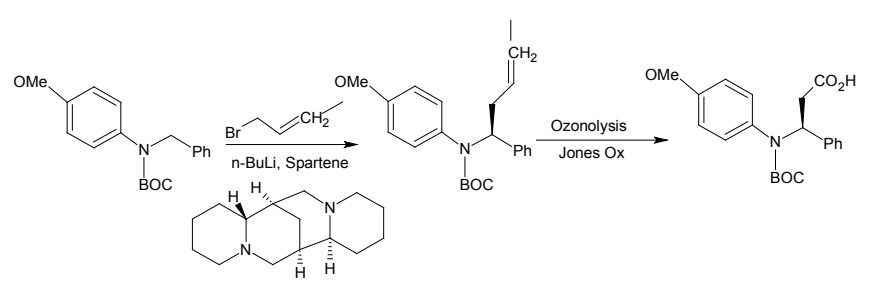

Scheme 49: Synthesis of $\beta$-phenyl amino acid from $N$ BOC- $N-(p-$ methoxyphenyl) benzylamine.

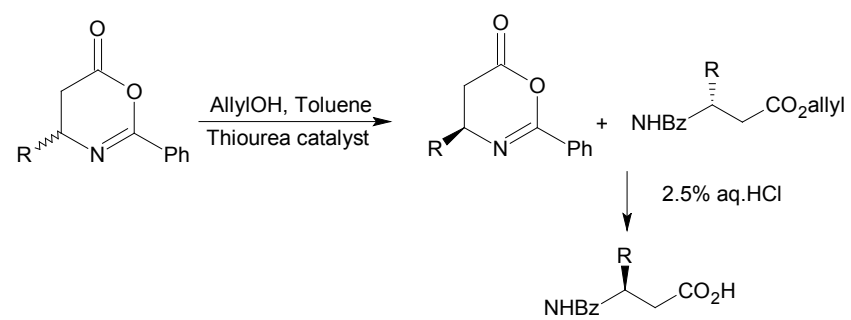

Scheme 50: Organo catalytic resolution of oxazinones.

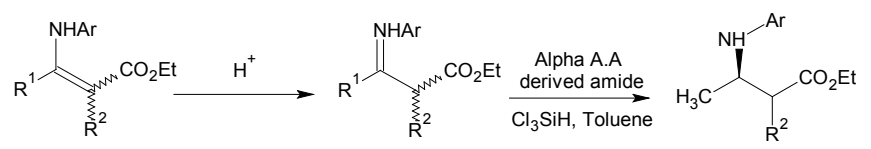

Scheme 51: Resolution of enamines towards $\beta$-amino acid derivatives.

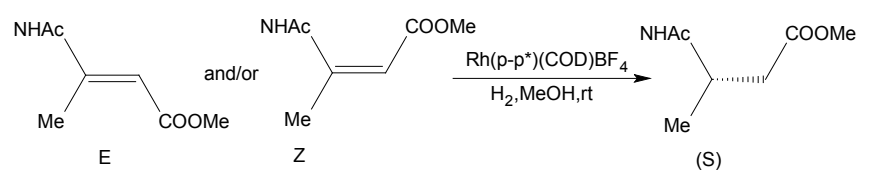

Scheme 52: The hydrogenation of (Z)- $\beta$-aminoacrylate towards $\beta$-amino acid synthesis.

oxazolines, easily derived from $\alpha$-amino acids, to yield $\beta$-amino acid derivatives is described in Scheme 53 [81].

A new set of reaction conditions has been established to facilitate the copper-catalyzedenantioselective 1,4 -reduction of $\beta$-(acylamino) acrylates toward a selection of $\beta$-alkyl- $\beta$-amino acid derivatives in high yield 99\% (Scheme 54) [82].

The chlorosulfonylisocyanate was reacted with cycloalkene to give fused $\beta$-lactams. The ring opening of the lactams was easily carried out with hydrochloric acid (Scheme 55) [83].

Cis- and trans- cyclohexane based $\beta$-amino acids, have also been prepared from the Diels-Alder adduct tetrahydroanthranilic anhydride (Scheme 56) [84-87]. The cis-isomer was prepared by ring-opening of this cyclic anhydride with aqueous ammonia to give the monoamide. Hoffman degradation of the resulting amide with hypobromite (or hypochlorite if a double bond was present) gave the $\beta$-amino acid. The synthesis of trans-cyclohexane required three additional steps. Esterification of anhydride gave the cis-diester and this was epimerised with sodium methoxide to give the trans-diester. Dehydration of this ester afforded the transanhydride, which was reacted to give the amine in two steps [88].

Enantiomerically pure cis $\beta$-amino acid was synthesised from diester (Scheme 57). Thisester was region specifically hydrolysed using pig liver esterase to give the monoester $[89,90]$. Reaction of this ester with sodium azide afforded the azide intermediate. A subsequent Curtius rearrangement of the azide gave the enantiomerically pure cis $\beta$-amino acid. In a related synthesis, epimerisation of the methyl ester to the trans-analogue gave the enantiomerically pure trans- $\beta$-amino acid [91].

A general enzymatically-catalysed synthesis of cyclic $\beta$-amino acids was reported by Forro et al. The $\beta$-lactam $( \pm)$ was enantioselectively hydrolysed with alipase B enzyme, giving cis $\beta$-amino acid. This resolved

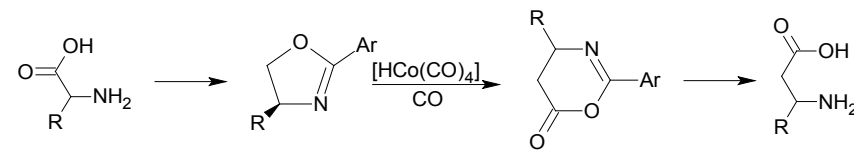

Scheme 53: The catalytic ring-expansive carbonylation of oxazolines.

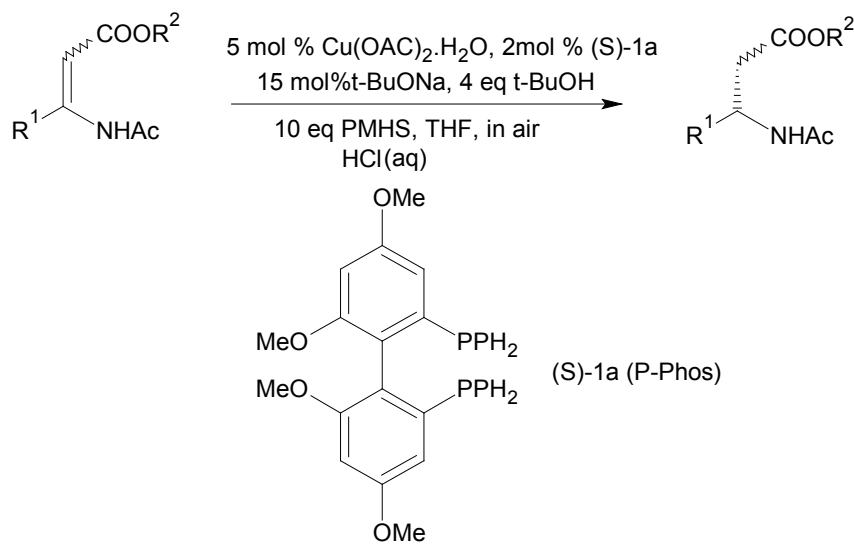

Scheme 54: The copper-catalyzed enantioselective 1, 4-reduction.

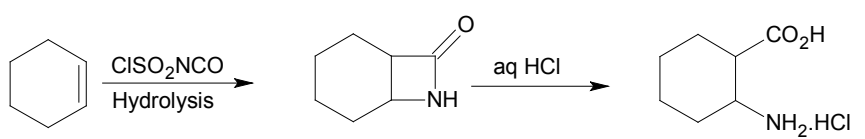

Scheme 55: Synthesis of $\beta$-amino acids through 1,2 cycloaddition.

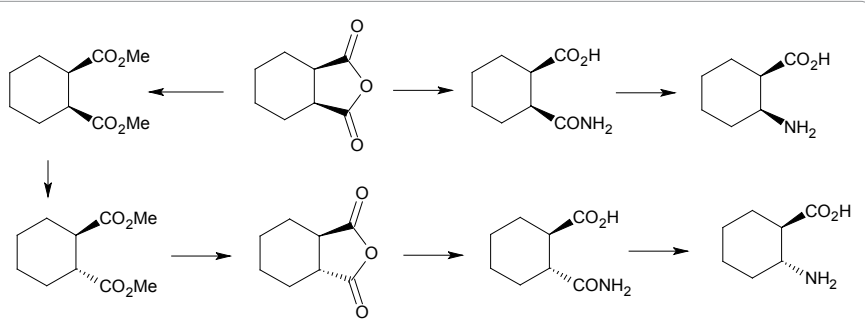

Scheme 56: Racemic synthesis of cis and trans ACHC.

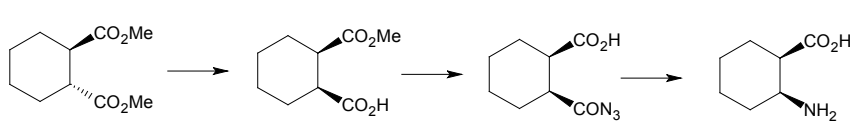

Scheme 57: Enantiomeric synthesis of cis-ACHC using enzymatic resolution. 
the other $\beta$-lactam enantiomer, which could then be hydrolysed nonenzymatically (Scheme 58) [92].

Another sequence which includes an enzymatic resolution involves the enantioselective acylation of $\beta$-amino acid $( \pm)$, to give the amide and resolving the other enantiomer (Scheme 59) [93, 94].

The use of chiral auxiliaries to introduce stereocentres into achiral molecules has proven very successful in the synthesis of $\beta$-amino acids. The racemic ketone $( \pm)$ was reacted with chiral $\alpha$-methyl benzylamine, to give the enantiomerically pure $\beta$-enamino ester intermediate was reduced by using sodium borohydride (Scheme 60) [95]. An alternative reduction at the more hindered face of enaminoester with sodium cyanoborohydride gave the corresponding trans $\beta$-amino acid $[96,97]$.

Davies et al. synthesized enantiomerically pure cyclic $\beta$-amino acids in $98 \%$ diastereomeric excess via conjugate addition of a chiral amine to cyclic $\alpha, \beta$-unsaturated esters (Scheme 61) [ 98, 99]. Stereoselective addition of the chiral amine, followed by aqueous quenching of the lithium enolate gave the cis as major isomer. The chiral amine moiety was hydrogenated with $\mathrm{Pd}(\mathrm{OH})_{2}$ to give the cyclopentane-based trans $\beta$-amino acid. This versatile general method was also used to synthesize novel heterocyclic $\beta$-amino acids [100].

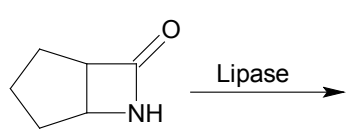

$(+)$
$\underbrace{\mathrm{mn}_{\mathrm{NH}_{2}}}_{\mathrm{n}=2,3} \stackrel{\text { acyldonar }}{\mathrm{CO}_{2} \mathrm{Me}}$

$( \pm)$
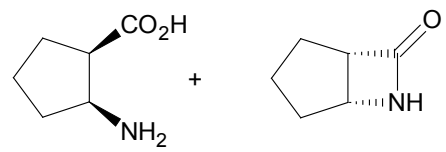

Scheme 58: Enzyme catalysed resolution of a racemic $\beta$-lactam.<smiles>CCOC(=O)C1CCCCC1=O</smiles><smiles>CCOC(=O)C1=C(NC(C)c2ccccc2)CCCC1</smiles><smiles>CC(=O)[C@H]1CCNC[C@H]1N</smiles>

$(+)$
Scheme 59: The enantioselective acylation of $\beta$-amino acid $\beta$-amino acid.
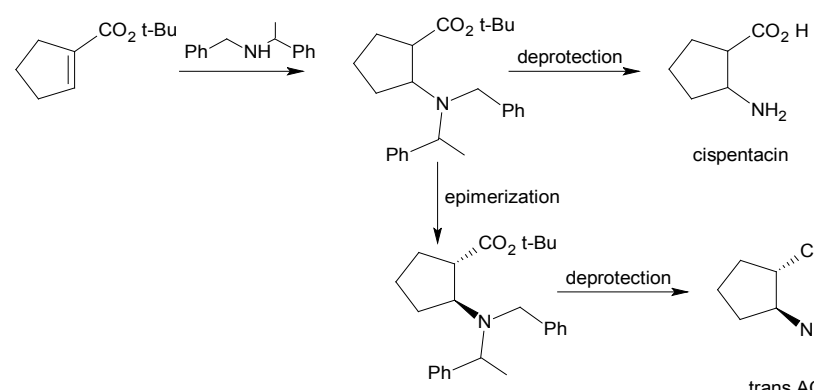

sentacin

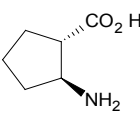

trans ACPC
Scheme 61: Diastereomeric synthesis of cis pentacin and trans ACPC.
Enders et al. synthesised cycloheptane based $\beta$-amino acids using a conjugate addition/alkylation reaction of $\alpha, \beta$-unsaturated ester (Scheme 62). This gave the cyclic chiral intermediate in $>96 \%$ yield was cleaved to $\beta$-amino acid $[67,68]$.

Enantioselective hydrogenation of the $\beta$-unsaturated ester using a ruthenium catalyst gave the $\beta$-amino ester, in up to $99 \%$ yield (Scheme 63). This reaction proved efficient for the synthesis of cyclopentane and cyclohexane. However, hydrogenation of seven- and eight-membered cycles gave lower diastereoselectivity [100].

A versatile method to synthesize cis or trans $\beta$-amino acids utilises a RCM approach using Grubb's $1^{\text {st }}$ and $2^{\text {nd }}$ generation ruthenium catalysts (Scheme 64 ). Allylation at the $\beta^{2}$ position gave the trans-diene, necessary for cyclization using Grubb's catalyst [101].

The stereoselective alkylation of oxazolidin 2-one-4-acetic acid derivative with inversions of stereochemistry is the main step for the synthesis of diastereomer of $\alpha, \beta$-disubstituted $\beta$-amino acid derivatives (Scheme 65) [102,103].

Such type of synthesis of stereoselective preparation of iturinic acid and 2-methyl-3-aminopropanoic acid also reported via alkylation mechanism is being described in scheme 66 [104].

Similar asymmetric synthesis of $\beta$-amino esters involved by the addition of silylenol ether to chiral imine generated in situ from

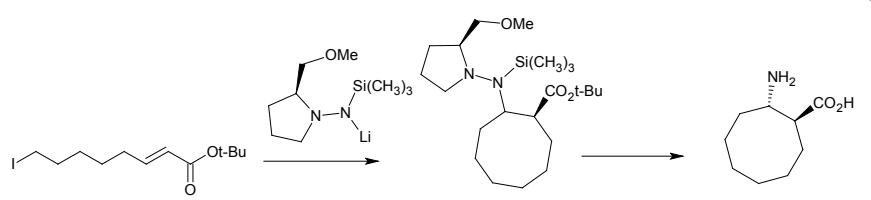

Scheme 62: The enantioselective synthesis of trans-2-amino-cycloheptane1-carboxylic acid.

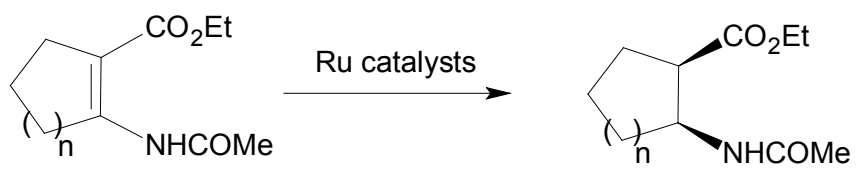

Scheme 63: Ruthenium-catalyzed enantioselective hydrogenation.

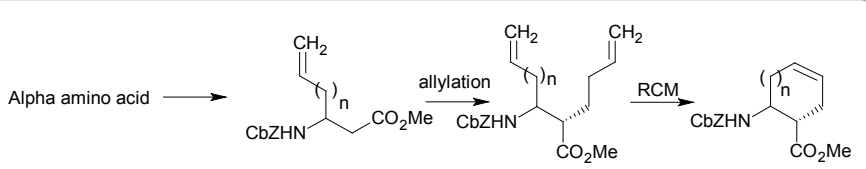

Scheme 64: Synthesis of cyclic $\beta$-amino acids via RCM

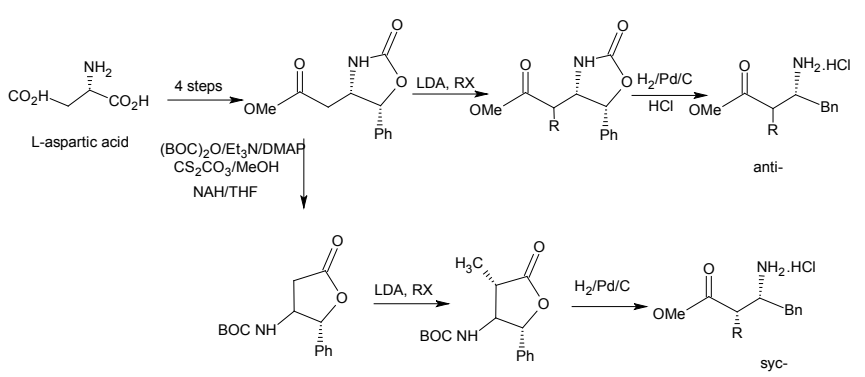

Scheme 65: Stereoselective alkylation of diastereomers of the $\alpha$, $\beta$-disubstituted $\beta$-amino acid. 
aldehydes and (S)-valine methyl ester described in scheme 67.All reactions were carried out at room temperature in $\mathrm{Yb}(\mathrm{OTf})_{3}$ catalyst to activate the imine and anhydrous $\mathrm{MgSO}_{4}$ to remove the water [105].

The synthesis of anti- $\alpha$-substituted- $\beta$-amino esters based on diastereoselective conjugate addition of $\mathrm{BnNH}_{2}$ was reported by Perlmutter and Tabone scheme 68 (a) [106]. In another recent report, Costa et al. were also able to add $\mathrm{BnNH}_{2}$ to choral esterin $90 \%$ yield scheme 68 (b) [107].

The conjugate addition of hydrazoic acid $\left(\mathrm{HN}_{3}\right)$ to $\alpha, \beta$-unsaturated imide scatalyzed by Chiral (salen)Al(III) complex was also described by Jacobsen et al. (Scheme 69).This procedure provided access to a variety of enantiopure $\beta$-alkyl- $\beta$-azido compounds. However, the addition to cinnamate was inefficient and reaction was incomplete [108].

Enantioselective hydrogenation of $\alpha, \beta$-unsaturated nitriles and their methyl esters bearing $\beta$-phthalimidomethyl substituents were reported by Jackson et al. (Scheme 70a,b).Surprisingly, only up to $48 \%$ yield was observed for Rh-DuPhos mediated hydrogenation of phthalimido nitriles. An improved selectivity (84\%) was achieved in the hydrogenation of phthalimido ester $(\mathrm{R}=\mathrm{H})$ using $\mathrm{Ru}-\mathrm{BINAP}$ as the catalyst. However, the $\beta$-substituent phthalimido ester $(\mathrm{R}=\mathrm{Me})$ resulted in a drastic decrease in yield (only 10\%) [109].

Juhl and Jørgensen reported anovel method to synthesize $\alpha$-hydroxy $\beta$-amino esters via asymmetric $\alpha$-amination and 2 -keto esters (Scheme 71). Dibenzylazodicarboxylate was acted as electrophilic

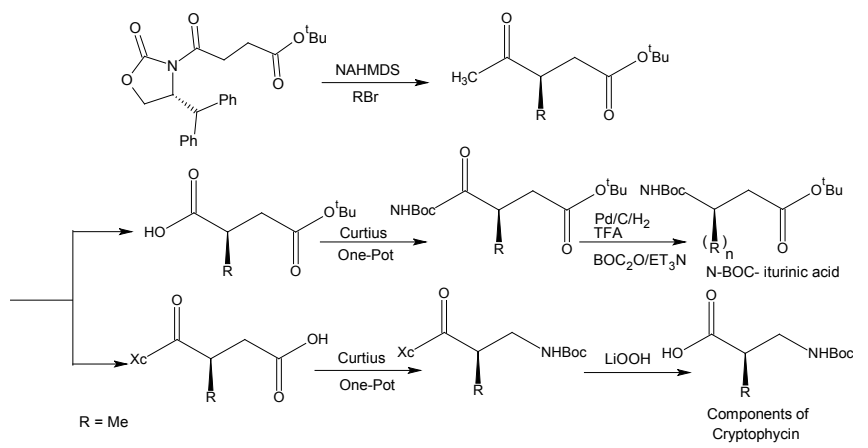

Scheme 66: Stereoselective preparation of iturinic acid and 2 methyl-3aminopropanoic acid.

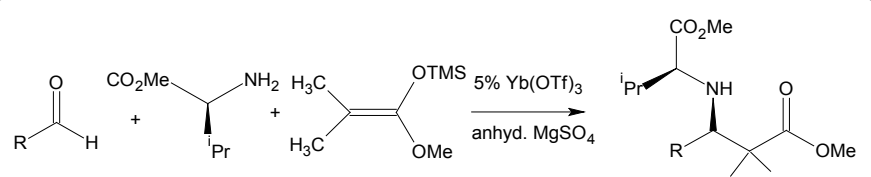

Scheme 67: Asymmetric synthesis of $\beta$-amino esters.

a)<smiles>[R]C(=O)C(=C)C([R])[R5](=O)[O-]</smiles>

b)

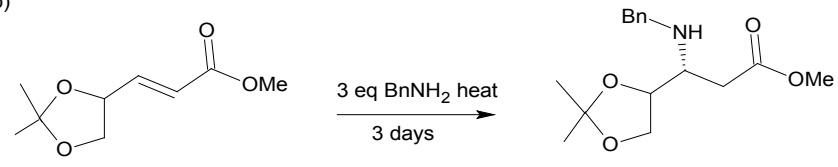

Scheme 68: The diastereoselective conjugate addition of $\mathrm{BnNH}_{2}$.<smiles>[R]C=CC(=O)NC(=O)c1ccccc1</smiles>

Scheme 69: The conjugate addition of hydrazoic acid $\left(\mathrm{HN}_{3}\right)$ to $\alpha, \beta$-unsaturated imide.
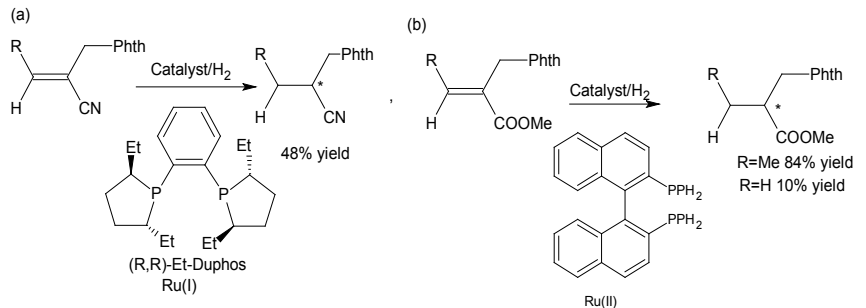

Scheme 70: Enantioselective hydrogenation of $\alpha, \beta$-unsaturated nitriles (a) and methyl (b) esters.

$$
\text { (I) }
$$

Scheme 71: The asymmetric $\alpha$-amination reaction of 2-keto esters.

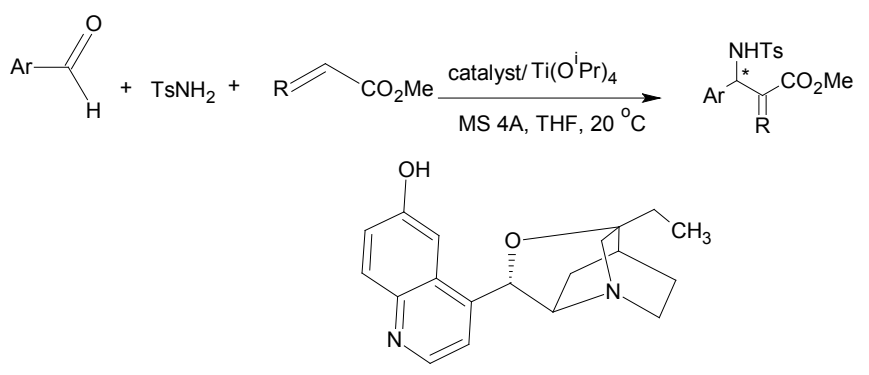

Quinnuclidine alkaloid derived catalyst

Scheme 72: Catalytic asymmetric Baylis-Hillman reaction.

nitrogen source. When THF gave higher \% yields with excellent levels of enantioselectivities [110].

When aromatic aldehydes added to sylamide and methylacrylate in the presence of nucleophilic quinuclidine alkaloid derived catalyst in combination with $\mathrm{Ti}\left(\mathrm{O}^{\mathrm{P} P r}\right)_{4}$ as Lewis acid,a good yield with moderate enantioselectivities were obtained (Scheme 72) [111].

Lectka et al. used bifunctional asymmetric catalyst and synthesized $\beta$-lactams from acyl chlorides and imine (Scheme 73). A combination of $\operatorname{In}(\mathrm{OTf})_{3}$ and quinidine derivative was used to obtain the syn- $\beta$ lactam with high yield [112].

Chiral Brønsted acid which was proposed to activate imine through hydrogen bonding was studied by Yamamoto et al. An achiral 
Brønstedacid $\left(\mathrm{R}^{3} \mathrm{OH}\right)$ protonates the amine moiety of the intermediate to give adducts in good yields. The addition of silylenolethers to aromatic aldimines was also catalyzed by Taddol-derived phosphoric acid with good yield as well (Scheme 74) [113,114].

$\mathrm{N}$-protected $\beta$-amino esters have been synthesized in good yield by Jørgensen et al. using the [1,3]-sigmatropic rearrangement of O-allylictrichloroacetimidates catalyzed by dihydroquinidine (DHQD) 2 PHAL (Scheme 75) [115].

The addition of nitrosobenzene to $\alpha, \beta$-unsaturated aldehydes was catalyzed by N-Heterocyclic carbine. This transformation gives isooxazolidinone intermediates which were hydrolyzed under acidic conditions to the corresponding methyl ester (Scheme 76) [116].

Waldmann et al. developed that imines while reacting with $\mathrm{N}$, $\mathrm{N}$-phthaloyl protected amino acid chloride lead to the $\mathrm{N}$-acyliminium intermediate, which was then subjected to nucleophilic attack (Scheme 77). It is interesting to note that excellent results were obtained if the aromatic groups of the imine carried an orthosubstituent [117].

The synthesis of $\alpha, \alpha$-difluoro- $\beta$-amino acid was reported by Quirion et al. using ethyl bromodifluoroacetate with chiral 1, 3-oxazolidines (Scheme 78a) [118]. Buttero et al. used a similar procedure in the addition of bromo esters to imines attached to atricarbonyl ( $\eta^{6}$ arene) chromium(0) complex (Scheme 78b) [119]. Shankar et al. synthesized $\beta$-lactams which were analogs of cholesterol absorption inhibitor SCH 48461 using chiral bromoacetate and imines (Scheme 78c) [120].

A large-scale asymmetric synthesis of cis-2 amino-1-cyclohexane carboxylate was reported by $\mathrm{Xu}$ et al. (Scheme 79a) [95]. Highest selectivity was obtained when the reaction was carried out in isobutyric acid and $\mathrm{NaBH}_{4}$ as hydride. A similar method using $\mathrm{NaCNBH}_{3}$ as the

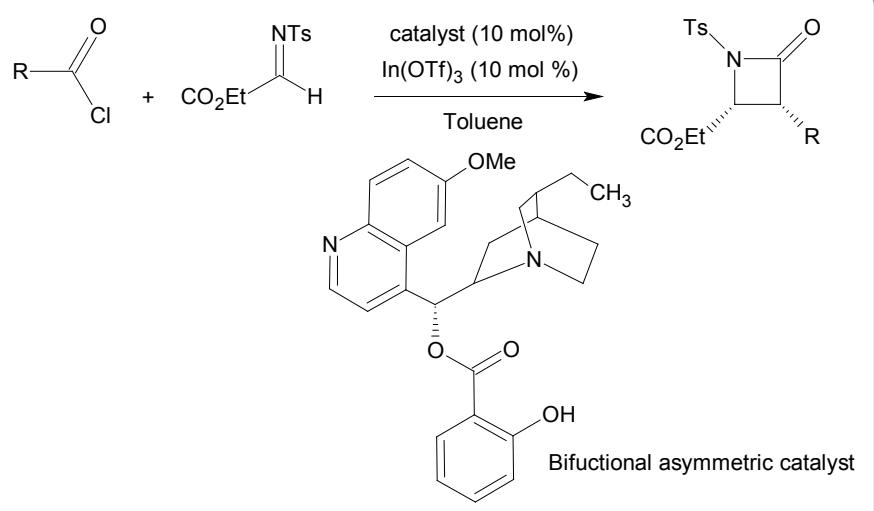

Scheme 73: A symmetric formation of $\beta$-lactams in quinidine catalyst.

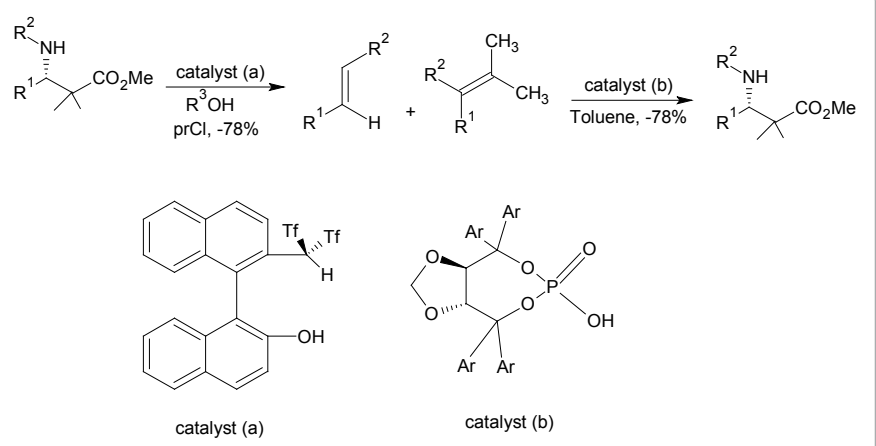
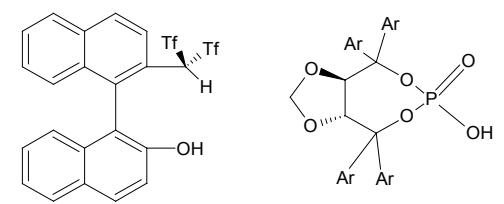

Scheme 74: Catalyst/ $\mathrm{H}_{2}$ Brønsted acid catalysed Mannich reactions synthesize $\beta^{2,2,3}$-amino acids.<smiles>[R]OC(=O)C([R])[R]([R])=O</smiles>

Scheme 75: $[1,3]-$ Sigmatropic rearrangement for the synthesis of $\beta$-amino esters.

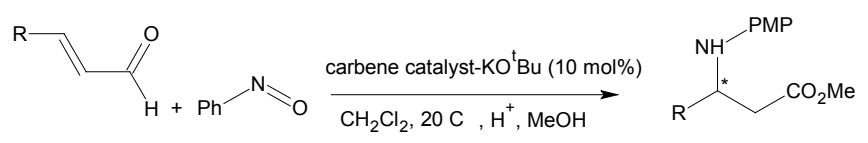

Scheme 76: Addition of $\alpha, \beta$-unsaturated aldehydes to nitrosobenzene.
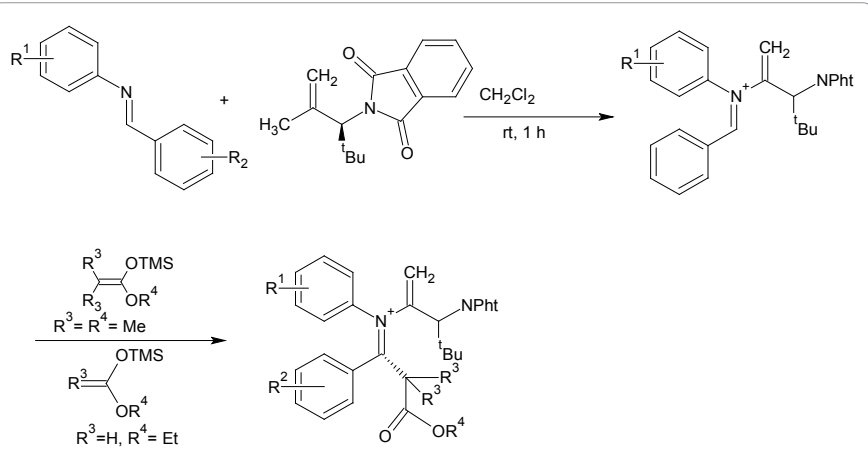

Scheme 77: Synthesis of $\beta$-amino acid via asymmetric Mannich reaction.

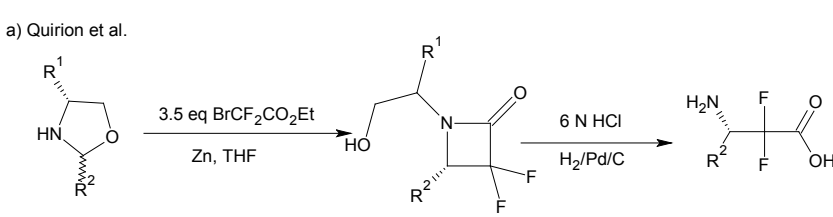

b) Buttero et al.<smiles>[R]C([R])(Br)C([R])([R])OCC</smiles>

c) Shankar et al.

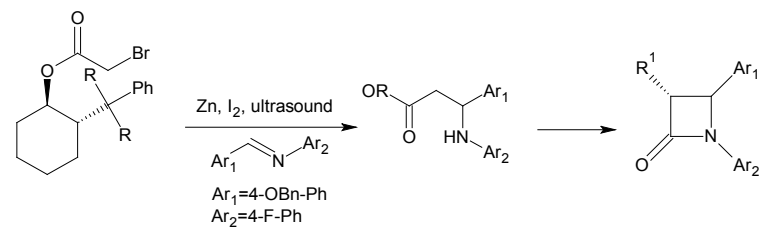

Scheme 78: Synthesis of $\beta$-amino acids.

reducing agent to prepare $\beta$-peptide building blocks (b) and (c) has also been explored by Gellmans' group (Scheme 79b,c) [96,97].

The enantioselective addition of lithium enolate to imine based on a ternary complex reagent was reported by Tomioka et al. $\beta$-Lactams were produced directly by the use of lithium cyclohexylisopropyl 
<smiles>CCOC(=O)C1CCCCC1N</smiles>

(a)

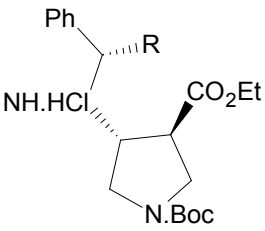

(b)

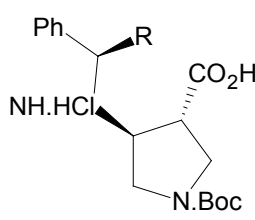

(c)
Scheme 79: Asymmetric synthesis of $\beta$-amino acids.<smiles>CCOC(OCC)=C(C)C</smiles>

Scheme 80: The asymmetric preparation of $\beta$-lactams.

$$
\text { (A) } \longrightarrow \text { (A) }
$$

Scheme 81: A novel biomimetic preparation of $\beta$-fluoroalkyl- $\beta$-amino acids.

amine or lithium dicyclohexyl amine as the additives with the highest enantioselectivity (Scheme 80) [121, 122].

A novel biomimetic preparation of $\beta$-fluoroalkyl- $\beta$-amino acids is given in scheme 81 . The process involved two consecutive base catalyzed 1,3-proton shift of enamine to aldimine, which was hydrolyzed to $\beta$-amino acids in $6 \mathrm{~N} \mathrm{HCl}$ [123-125].

\section{Conclusions}

A tremendous progress has been made in the past decades forthe enantiopure synthesis of $\beta$-amino acids and derivatives on account of bearing varieties of biological activities including antifungal, antitubercular, antibacterial and anticancer. They are also used in the treatment of many diseases and health issues.Therefore, enantioselective $\beta$-amino acids have potential therapeutic values and are a great challenge for chiral synthesis.Therefore, $\beta$-amino acids with various substitution patterns are now available. Each approach has itsown advantages and limitations while more than 80 numbers of different approaches have been discussed here but the organo-Rh based and heterogeneous catalyzed approach is found to be more effective (Scheme 1, 2, 4,11, 12, 13, 28, 29) and (Scheme 8, 9, 33, 34, 35, 36, $37,45,54,63)$. Other approaches can also be considered to synthesize enantioselective amino acids (Scheme 11, 13, 15, 40, 45, 50, 61, 62, 68, $70,74)$. No doubt, the growing interest in enantioselective $\beta$-amino acids will stimulate new and improved methods for their synthesis in near future.

\section{References}

1. Shinagawa S, Kanamaru T, Harada S, Asai M, Okazaki H (1987) Chemistry and inhibitory activity of long chain fatty acid oxidation of emeriamine and its analogues.J Med Chem 30: 1458-1463.
2. Kanamaru T, Shinagawa S, Asai M, Okazaki H, Sugiyama Y, et al. (1985) Emeriamine, an antidiabetic beta-aminobetaine derived from a novel fungal metabolite. Life Sci 37: 217-223.

3. Juaristi E (1997) Enantioselective Synthesis of ß-Amino Acids. Wiley-VCH: New York. Chapter 1: 491.

4. Namikoshi M, Rinehart KL, Dahlem AM, Beasley VR, Carmichael WW (1989) Total synthesis of Adda, the unique C20 amino acid of cyanobacterial hepatotoxins. Tetrahedron Lett 30: 4349-4352.

5. von Nussbaum F, Spiteller P, Ru“th M, Steglich W, Wanner G (1998) An Iron(III)Catechol Complex as a Mushroom Pigment. Angew Chem Int Ed 37: 3292.

6. Spiteller $P, R \tilde{A}^{1 / 4 t h} M$, von Nussbaum F, Steglich W (2000) Detection of a 2,3-Aminomutase in the Mushroom Cortinarius violaceus This contribution was supported by the Deutsche Forschungsgemeinschaft (SFB 369). Angew Chem Int Ed Engl 39: 2754-2756.

7. Crews $P$, Manes LV, Boehler M (1986) Jasplakinolide, a cyclodepsipeptide from the marine sponge, SP. Tetrahedron Lett 27: 2797-2800.

8. Shih C, Gossett LS, Gruber JM, Grossman CS, Andis SL, et al. (1999) Synthesis and biological evaluation of novel cryptophycin analogs with modification in the beta-alanine region.Bioorg Med Chem Lett 9: 69-74.

9. Roers R, Verdine GL (2001) Concise enantio- and diastereoselective synthesis of $\alpha$-hydroxy- $\alpha$-methyl- $\beta$-amino acids. Tetrahedron Lett 42: 3563.

10. Lubell WD, Kitamura M, Noyori R (1991) Enantioselective synthesis of $\beta$-amino acids based on BINAP—ruthenium(II) catalyzed hydrogenation. Tetrahedron Asym 2: 543-554.

11. Tang W, Wang W, Chi $Y$, Zhang $X$ (2003) A bisphosphepine ligand with stereogenic phosphorus centers for the practical synthesis of beta-aryl-betaamino acids by asymmetric hydrogenation. Angew Chem Int Ed Engl 42: 3509 3511.

12. Komarov IV, Börner A (2001) Highly Enantioselective or Not?-Chiral Monodentate Monophosphorus Ligands in the Asymmetric Hydrogenation. Angew Chem Int Ed Engl 40: 1197-1200.

13. Huang H, Liu X, Deng J, Qiu M, Zheng Z (2006) Rhodium-catalyzed enantioselective hydrogenation of beta-phthalimide acrylates to synthesis of beta2-amino acids.Org Lett 8: 3359-3362.

14. Wilsily A, Fillion E (2008) Asymmetric synthesis of carboxylic acid derivatives having an all-carbon alpha-quaternary center through Cu-catalyzed ,4-addition of dialkylzinc reagents to 2-aryl acetate derivatives.Org Lett 10: 2801-2804.

15. Sibi MP, Tatamidani H, Patil K (2005) Enantioselective rhodium enolate protonations. A new methodology for the synthesis of beta2-amino acids. Org Lett 7: 2571-2573.

16. Yuan C Williams RM (1997) Total Synthesis of the Anti Methicillin-Resistant Staphylococcus aureus Peptide Antibiotics TAN-1057A-D. J Am Chem Soc 119: 11777-11784

17. Caputo R, Cassano E, Longobardo L, Palumbo G (1995) Synthesis of Enantiopure $\mathrm{N}$-and $\mathrm{C}$-Protected homo- $\beta$-Amino Acids by Direct Homologation of a-Amino Acids. Tetrahedron 51: 12337-12350.

18. Sammis GM, Jacobsen EN (2003) Highly enantioselective, catalytic conjugate addition of cyanide to alpha,beta-unsaturated imides. J Am Chem Soc 125 4442-4443.

19. Hamashima Y, Somei H, Shimura Y, Tamura T, Sodeoka M (2004) Aminesalt-controlled, catalytic asymmetric conjugate addition of various amines and asymmetric protonation.Org Lett 6: 1861-1864.

20. Liu H, Xu J, Du DM (2007) Asymmetric Friedel-Crafts alkylation of methoxyfuran with nitroalkenes catalyzed by diphenylamine-tethered bis(oxazoline)-Zn(II) complexes.Org Lett 9: 4725-4728.

21. Gedey S, Liljeblad A, Lazar L, Fülöp F, Kanerva LT (2001) Preparation of highly enantiopure $\beta$-amino esters by Candida antarctica lipase $A$. Tetrahedron: Asymmetry 12: 105-110.

22. Gedey S, Liljeblad A, Fülöp F and Kanerva LT (1999) Sequential resolution of ethyl 3-aminobutyrate with carboxylic acid esters by Candida antarctica lipase B. Tetrahedron: Asymmetry 10: 2573-2581.

23. Sanchez VM, Rebolledo F, Gotor V (1997) Candida Davies antarctica lipase catalyzed resolution of ethyl ( \pm )-3-aminobutyrate. Tetrahedron: Asymmetry 8 : $37-40$.

24. Soloshonok VA, Fokina NA, Rybakova AV, Shishkina IP, Galushko SV, et 
al. (1995) Biocatalytic approach to enantiomerically pure $\beta$-amino acids. Tetrahedron: Asymmetry 6: 1601-1610.

25. Davies HM, Venkataramani C (2002) Catalytic enantioselective synthesis of beta3-amino acids. Angew Chem Int Ed Engl 41: 2197-2199.

26. Wenzel AG, Jacobsen EN (2002) Asymmetric catalytic Mannich reactions catalyzed by urea derivatives: enantioselective synthesis of beta-aryl-betaamino acids. J Am Chem Soc 124: 12964-12965.

27. Lurain AE, Walsh PJ (2003) A catalytic asymmetric method for the synthesis of gamma-unsaturated beta-amino acid derivatives. J Am Chem Soc 125: $10677-$ 10683.

28. Utsumi N, Kitagaki S, Barbas CF 3rd (2008) Organocatalytic mannich-type reactions of trifluoroethyl thioesters. Org Lett 10: 3405-3408.

29. Ponsinet R, Chassaing G, Vaissermann J, Lavielle S (2000) Diastereoselective Synthesis of $\beta 2-$ Amino Acids. Eur J Org Chem 83-90.

30. Ibrahem I, Córdova A (2005) Amino acid-catalyzed direct enantioselective synthesis of $\beta$-amino- $\alpha$-oxyaldehydes. Tetrahedron Lett 46: 2839.

31. Dziedzic P, Vesely J, Córdova A (2008) Catalytic asymmetric synthesis of the docetaxel (Taxotere) side chain: organocatalytic highly enantioselective synthesis of esterification-ready $\alpha$-hydroxy- $\beta$-amino acids. Tetrahedron Lett 49 : $6631-6634$.

32. Yang JW, Stadler M, List B (2007) Proline-catalyzed mannich reaction of aldehydes with N-boc-imines. Angew Chem Int Ed Engl 46: 609-611.

33. Davies SG, Ichihara O (1991) Asymmetric synthesis of R- $\beta$-amino butanoic acid and S- $\beta$-tyrosine: Homochiral lithium amide equivalents for Michael additions to $\alpha, \beta$-unsaturated esters. Tetrahedron: Asymmetry 2: 183-186.

34. Davies SG, Ichihara O, Lenoir I, Walters IAS (1994) Molecular recognition directed self-assembly of supramolecular cylindrical channel-like architectures from $6,7,9,10,12,13,15,16$-octahydro-1,4,7,10,13-pentaoxabenzocyclopentadecen2-ylmethyl 3,4,5-tris(p-dodecyloxybenzyloxy)benzoate. Journal of the Chemical SocietyPerkin Transactions 1: 1411-1420.

35. Ishikawa T, Nagai K, Kudoh T, Saito S (1995) Asymmetric-Synthesis of Substituted Isoxazolidinone from $\alpha, \beta$-unsaturated Esters and Hydroxylamines by Means of Double Stereodifferentiation. Synlett. 11: 1171-1173.

36. Sibi MP, Itoh K (2007) Organocatalysis in conjugate amine additions: synthesis of beta-amino acid derivatives. J Am Chem Soc 129: 8064-8065.

37. Kim J, Kyung D, Yun H, Cho BK, Seo JH, et al. (2007) Cloning and characterization of a novel beta-transaminase from Mesorhizobium sp. strain LUK: a new biocatalyst for the synthesis of enantiomerically pure beta-amino acids. Appl Environ Microbiol 73: 1772-1782.

38. Klettke KL, Sanyal S, Mutatu W, Walker KD (2007) Beta-styryl- and beta-arylbeta-alanine products of phenylalanine aminomutase catalysis.J Am Chem Soc 129: 6988-6989.

39. Wu B, Szymanski W, Wietzes P, de Wildeman S, Poelarends GJ, et al (2009) Enzymatic synthesis of enantiopure alpha- and beta-amino acids by phenylalanine aminomutase-catalysed amination of cinnamic acid derivatives. Chembiochem 10: 338-344.

40. Hodous BL, Fu GC (2002) Enantioselective Staudinger synthesis of betalactams catalyzed by a planar-chiral nucleophile.J Am Chem Soc 124: 15781579.

41. Warmerdam EGJC, van Rijn RD, Brussee J, Kruse CG, van der Gen A (1996) Synthesis of $\alpha$-hydroxy- $\beta$-amino acids from chiral cyanohydrins. Tetrahedron: Asymmetry 7: 1723-1732

42. Hsiao Y, Rivera NR, Rosner T, Krska SW, Njolito E, et al. (2004) Highly efficien synthesis of beta-amino acid derivatives via asymmetric hydrogenation of unprotected enamines.J Am Chem Soc 126: 9918-9919.

43. Holz J, Monsees A, Jiao H, You J, Komarov IV, et al. (2003) Synthesis of a new chiral bisphospholane ligand for the $\mathrm{Rh}(\mathrm{I})$-catalyzed enantioselective hydrogenation of isomeric beta-acylamido acrylates. J Org Chem 68: 17011707.

44. Hoen R, Tiemersma-Wegman T, Procuranti B, Lefort L, de Vries JG, et al. (2007) Enantioselective synthesis of beta2-amino acids using rhodiumcatalyzed hydrogenation.Org Biomol Chem 5: 267-275.

45. Hamashima Y, Sasamoto N, Hotta D, Somei H, Umebayashi N, et al. (2005) Catalytic asymmetric addition of beta-ketoesters to various imines by using chiral palladium complexes. Angew Chem Int Ed Engl 44: 1525-1529.
46. Morimoto H, Lu G, Aoyama N, Matsunaga S, Shibasaki M (2007) Lanthanum aryloxide/pybox-catalyzed direct asymmetric Mannich-type reactions using a trichloromethyl ketone as a propionate equivalent donor.J Am Chem Soc 129 9588-9589.

47. Chen Z, Morimoto H, Matsunaga S, Shibasaki M (2008) A bench-stable homodinuclear Ni2-Schiff base complex for catalytic asymmetric synthesis of alpha-tetrasubstituted anti-alpha, beta-diamino acid surrogates.J Am Chem Soc 130: $2170-2171$

48. Salter MM, Kobayashi J, Shimizu Y, Kobayashi S (2006) Direct-type catalytic three-component mannich reactions leading to an efficient synthesis of alpha,beta-diamino acid derivatives.Org Lett 8: 3533-3536.

49. Yamashita Y, Ueno M, Kuriyama Y, Kobayashi S (2002) Catalytic Asymmetric Mannich-Type Reactions Using a Novel Chiral Iron Complex. Adv Synth Catal 344: 929-931.

50. Duursma A, Minnaard AJ, Feringa BL (2003) Highly enantioselective conjugate addition of dialkylzinc reagents to acyclic nitroalkenes: a catalytic route to beta2-amino acids, aldehydes, and alcohols.J Am Chem Soc 125: 3700-3701.

51. Li K, Mimi Hii KK (2003) Dicationic [(BINAP)Pd(solvent)2]2+[TfO-]2 enantioselective hydroamination catalyst for alkenoyl- $\mathrm{N}$-oxazolidinones. Chem Commun 1132-1133.

52. Li K, Cheng X, Hii KKM (2004) Asymmetric Synthesis of $\beta$-Amino Acid and Amide Derivatives by Catalytic Conjugate Addition of Aromatic Amines to N-Alkenoylcarbamates. Eur J Org Chem 5: 959-964.

53. Chi Y, Gellman SH (2006) Enantioselective organocatalytic aminomethylation of aldehydes: a role for ionic interactions and efficient access to beta2-amino acids.J Am Chem Soc 128: 6804-6805.

54. Chi Y, English EP, Pomerantz WC, Horne WS, Joyce LA, et al. (2007) Practical synthesis of enantiomerically pure $\beta 2$-amino acids via proline-catalyzed diastereoselective aminomethylation of aldehydes. J Am Chem Soc 129 6050-6055.

55. Ibrahem I, Zhao GL, Córdova A (2007) Direct catalytic enantioselective alphaaminomethylation of aldehydes. Chemistry -A Eur J 13: 683-688.

56. Chen YK, Yoshida M, MacMillan DW (2006) Enantioselective organocatalytic amine conjugate addition.J Am Chem Soc 128: 9328-9329.

57. Vesely J, Ibrahem I, Rios R, Zhao GL, Xu Y, Córdova A (2007) Enantioselective organocatalytic conjugate addition of amines to $\alpha, \beta$-unsaturated aldehydes: one-pot asymmetric synthesis of $\beta$-amino acids and 1,3-diamines. Tetrahedron Lett 48: 2193-2198.

58. Ibrahem I, Rios R, Vesely J, Zhao GL, Córdova A (2008) Catalytic Enantioselective 5-Hydroxyisoxazolidine Synthesis: An Asymmetric Entry to $\beta$-Amino Acids. Synthesis 7: 1153-1157.

59. Beaulieu F, Arora J, Veith U, Taylor NJ, Chapell BJ, Snieckus V (1996) 1,3-Asymmetric Induction via 1,5-Hydrogen Atom Translocation Reactions. Highly Enantioselective Synthesis of $\beta$-Substituted $\beta$-Amino Acids. J Am Chem Soc 118: 8727-8728.

60. Cardillo G, Gentilucci L (1998) Chelation-Controlled Regioselectivity in the Synthesis of Substituted Pyrazolylpyridine Ligands. 3. Unsymmetrically Substituted Tridentates and Ditopic Bis(tridentates) en Route to Singly Stranded Helicates. J Org Chem 63: 235-240.

61. Davis FA, Szewczyk JM, Reddy R.E (1996) An Efficient Synthesis of (S)-(+)Ethyl $\alpha$-Amino-3-pyridinepropanoate Using Enantiopure Sulfinimines. J Org Chem 6: 2222-2225.

62. Davis FA, Reddy GV, Liang CH, (1997) Aziridine 2-Carboxylate Ester Mediated Asymmetric Syntheis of $\alpha$-Alkyl $\beta$-Aminoacids. Tetrahedron Lett 38: 5139-5142.

63. Tang TP, Ellman JA (1999) The tert-Butanesulfinyl Group: An Ideal Chira Directing Group and Boc-Surrogate for the Asymmetric Synthesis and Applications of beta-Amino Acids. J Org Chem 64: 12-13.

64. Vicario JL, Badi'a D, Carrillo L (2001) Asymmetric synthesis of betasubstituted alpha-methyl-beta-amino esters by Mannich reaction of $(\mathrm{S}, \mathrm{S})-(+)-$ pseudoephedrine acetamide derived enolate with imines. Org Lett 3: 773-776.

65. Ma Z, Zhao Y, Jiang N, Jin X, Wang J (2002) Stereoselective nucleophilic addition of chiral lithium enolates to ( $\mathrm{N}$-tosyl)imines: enantioselective synthesis of $\beta$-aryl- $\beta$-amino acid derivatives. Tetrahedron Lett 43: 3209-3212.

66. Roos GHP, Balasubramaniam S (1999) Diastereoselective Addition of Imidazolidin-2-One Controlled Enolates to Activated Imines. Synth Commun 29: 755-762. 
67. Enders D, Wahl H, Bettray W (1995) Enantioselective Synthesis of $\beta$-Amino Acids: TMS-SAMP as a Chiral Ammonia Equivalent for the Aza Analogous Michael Addition to $\alpha, \beta-$ Unsaturated Esters. Angew Chem Int Ed Engl 34: 455-457.

68. Enders D, Wiedemann J, Bettray W (1995) Diastereo- and Enantioselective Synthesis of trans-2-Amino-Cycloalkane-1-Carboxylic Acids via Intramolecular Tandem Michael-Addition/a-Alkylation Using TMS-SAMP as Chiral Equivalent of Ammonia. Synlett 369-371.

69. Sibi MP, Chen J (2002) Enantioselective conjugate addition of silylketene acetals to beta-enamidomalonates. Synthesis of beta-amino acid derivatives. Org Lett 4: 2933-2936.

70. Ponsinet R, Chassaing G, Lavielle S (1998) Asymmetric synthesis of Boc- $\beta 2$ homophenylglycine. Tetrahedron: Asymmetry 9: 865-871.

71. Calmes M, Escale F (1998) New synthesis of enantiomerically pure (S)-3 amino-2-phenyl propanoic acid via the asymmetric transformation of its racemic N-phthaloyl derivative. Tetrahedron: Asymmetry 9: 2845-2850.

72. Prashad M, Kim HY, Lu Y, Liu Y, Har D, et al. (1999) The First Enantioselective Synthesis of $\left(2 R, 2^{\prime} R\right)$-threo-(+)-Methylphenidate Hydrochloride.J Org Chem 64: $1750-1753$

73. Axten JM, Krim L, Kung HF, Winkler JD (1998) A Stereoselective Synthesis of dl-threo-Methylphenidate: Preparation and Biological Evaluation of Novel Analogues J Org Chem 63: 9628-9629.

74. Dubrovina NV, Tararov VI, Monsees A, Kadyrov R, Fischer C, et al. (2003) Economic preparation of 1,3-diphenyl-1,3-bis(diphenylphosphino)propane: a versatile chiral diphosphine ligand for enantioselective hydrogenations. Tetrahedron Asym 14: 2739-2745.

75. Kim BJ, Park YS, Beak P (1999) Asymmetric Syntheses of Derivatives of betaand gamma-Aryl and alpha-Alkyl Amino Acids Using n-BuLi/(-)-Sparteine. J Org Chem 64: 1705-1708

76. Berkessel A, Cleemann F, Mukherjee S (2005) Kinetic Resolution of Oxazinones: An Organocatalytic Approach to Enantiomerically Pure $\beta$-Amino Acids. Angew Chem Int Ed 44: 7466-7469.

77. Malkov AV, Stončius S, Vranková K, Arndt M, Kočovský P (2008) Dynamic Kinetic Resolution in the Asymmetric Synthesis of $\beta$-Amino Acids by Organocatalytic Reduction of Enamines with Trichlorosilane Chem A Eur J 14: 8082-8085.

78. Heller D, Holz J, Drexler HJ, Lang J, Drauz K, et al. (2001) Pressure dependent highly enantioselective hydrogenation of unsaturated beta-amino acid precursors.J Org Chem 66: 6816-6817.

79. Engel U, Syldatk C, Rudat J (2012) Stereoselective hydrolysis of arylsubstituted dihydropyrimidines by hydantoinases. Appl Microbiol Biotechnol 94: 1221-1231.

80. Rudat J, Brucher BR, Syldatk C, (2012)Transaminases for the synthesis of enantiopure beta-amino acids. AMB Express 2: 1-10

81. Byrne CM, Church TL, Kramer JW, Coates GW (2008) Catalytic Synthesis of $\beta^{3}$-Amino Acid Derivatives from $\alpha$-Amino Acids. Angew Chem Int Ed 47: 39793983.

82. Wu Y, Qi SB, Wu FF, Zhang XC, Li M, Wu J, Chan ASC (2011) Synthesis of $\beta$-Amino Acid Derivatives via Copper-Catalyzed Asymmetric 1,4-Reduction of $\beta$-(Acylamino)acrylates. Org Lett 13: 1754-175.

83. Nativ E, Rona P (1972) 2-Azabicyclo [3.2.0] Heptane-3-One. Israel Journal of Chemistry 10: 55-58.

84. Bernath G, Kovacs K, Lang KL (1970) Stereochemical studies. VII. Cyclic aminoalcohols and related compounds. I. Stereospecific synthesis of cis- and trans-2-aminomethyl-cyclohexanol and cis- and trans-2hydroxymethylcyclohexyl-amine. Acta Chimica Academiae Scientarium Hungaricae 64: 183-197.

85. Plieninger $\mathrm{H}$, Schneider $\mathrm{K}$ (1959) The addition of ammonia to D1tetrahydrobenzoic acid and 1-cyclopentene-1-carboxylic acid and the unequivocal steric classification of the resulting b-amino acids Chemische Berichte-Recueil 92: 1594-1609.

86. Bernath G, Gondos G, Kovacs K, Sohar P (1973) Stereochemical studies-XVII: Cyclic aminoalcohols and related compounds-IX synthesis and NMR study of stereoisomeric cis- and trans-tetramethylene- and pentamethylene-1,3oxazine-2-ones. Tetrahedron 29: 981-984.

87. Bernath G, Gera L, Gondos G, Panovics I, Ecsery Z (1976) Stereochemical studies, XXVI. Acid amides of potential pharmacological activity, II. The synthesis of cis- and trans-2-amino-1-cyclopentane-, -1-cyclohexane- and -1-cycloheptanecarboxamide derivatives. Acta Chimica Academia Scientiarum Hungaricae 89: 61-84.

88. Bernath G, Stajer G, Szabo AE, Fulop F, Sohar P (1985) Stereochemical studies 83 saturated heterocycles 76 : Preparation and conformational study of partially saturated 3,1-benzoxazines, 3,1-benzoxazin-2-ones and 3,1-benzoxazine-2thiones. Tetrahedron 41: 1353-1365.

89. Kurihara MA, Kamiyama K, Kobayashi S, Ohno M (1985) Synthetic carbapenem antibiotics II. Stereoisomers of 7-hydroxyethyl-2,2,5-trimethyl-3 oxa-1-azabicyclo[4.2.O]octan-8-one. Tetrahedron Letters 26: 583-586.

90. Kaga H, Kobayashi S, Ohno M (1988) An enantioselective synthesis of a key intermediate to thienamycin by chemicoenzymatic approach. Tetrahedron Letters 29: 1057-1060.

91. Kobayashi S, Kamiyama K, Ohno M (1990) Chiral synthon obtained with pig liver esterase: introduction of chiral centers into cyclohexene skeleton.Chem Pharm Bull (Tokyo) 38: 350-354.

92. Forro E, Fulop F (2003) Lipase-catalyzed enantioselective ring opening of unactivated alicyclic-fused beta-lactams in an organic solvent.Org Lett 5: 12091212.

93. Gyarmati ZC, Liljeblad A, Rintola M, Bernath G, Kanerva LT (2003) Lipasecatalyzed kinetic resolution of 7-, 8- and 12-membered alicyclic $\beta$-amino esters and N-hydroxymethyl- $\beta$-lactam enantiomers. Tetrahedron: Asymmetry 14 3805-3814.

94. Forro E, Arva J, Fulop F (2001) Preparation of (1R,8S)- and (1S,8R)-9 azabicyclo[6.2.0]dec-4-en-10-one: potential starting compounds for the synthesis of anatoxin-a. Tetrahedron: Asymmetry 12: 643-649.

95. Xu D, Prasad K, Repic O, Blacklock TJ (1997) A Practical Synthesis of Enantiopure ethyl cis-2-amino-1-Cyclohexanecarboxylate via Asymmetric Reductive Amination Methodology. Tetraedron Asymmetry 8: 1445-1451.

96. Lee HS, LePlae PR, Porter EA, Gellman SH (2001) An Efficient Route to Either Enantiomer of Orthogonally Protected trans-3-Aminopyrrolidine-4-carboxylic Acid. J Org Chem 66: 3597-3599.

97. LePlae PR, Umezawa N, Lee HS, Gellman SH (2001) An efficient route to either enantiomer of trans-2-aminocyclopentanecarboxylic acid. J Org Chem 66: $5629-5632$.

98. Davies SG, Ichihara O, Walters IAS (1993) An Expeditious Asymmetric Synthesis of (-)-(1R,2S) -Cispentacin. Synlett 7: 461-462.

99. Davies SG, Ichihara O, Lenoir I, Walters IAS (1994)Molecular recognition directed self-assembly of supramolecular cylindrical channel-like architectures from $6,7,9,10,12,13,15,16$-octahydro-1,4,7,10,13-pentaoxabenzocyclopentadecen2-ylmethyl 3,4,5-tris(p-dodecyloxybenzyloxy)benzoate. Journal of the Chemical Society Perkin Transactions 1: 1411-1420.

100.Davies SG, Smith AD, Price PD (2005) The conjugate addition of enantiomerically pure lithium amides as homochiral ammonia equivalents: scope, limitations and synthetic applications. Tetrahedron-Asymmetry 16 2833-2891

101. Gardiner J, Anderson KH, Downard A, Abell AD (2004) Synthesis of Cyclic B-Amino Acid Esters from Methionine, Allylglycine, and Serine. Journal of Organic Chemistry 69: 3375-3382.

102. Seki M, Matsumoto K (1996) A novel approach to homochiral $\beta$-amino acids. Tetrahedron Lett 37: 3165-3168.

103. Seki M, Shimizu T, Matsumoto K (2000) Stereoselective Synthesis of $\beta$-Benzyl$\alpha$-alkyl- $\beta$-amino Acids from L-Aspartic Acid. J Org Chem 65: 1298-1304.

104.Sibi MP, Deshpande PK (2000) A new methodology for the synthesis of $\beta$-amino acids. J Chem Soc Perkin Trans1 1461-1466.

105. Cozzi PG, Simone BD, Umani-Ronchi A (1996) Highly diastereoselective addition of silyl enolates to chiral imines derived from (S)-valine methyl ester using lanthanide triflate. Tetrahedron Lett 37: 1691-1694.

106.Perlmutter P, Tabone MJ (1995) A Simple Route to $\alpha$-Substituted $\beta$ Amino Ester Precursors of Carbapenem Antibiotics. J Org Chem 60: 6515-6522.

107. Lima PG, Sequeira LC, Costa PRR (2001) Synthesis of $\beta$-amino arylketones through the addition of ArLi derivatives to $\beta$-aminoesters. Tetrahedron Lett 42 : 3525-3527.

108. Myers JK, Jacobsen EN (1999) Asymmetric Synthesis of $\beta$-Amino Acid Derivatives via Catalytic Conjugate Addition of Hydrazoic Acid to Unsaturated mides. J Am Chem Soc 121: 8959-8960. 
Citation: Ashfaq M, Tabassum R, Ahmad MM, Hassan NA, Oku H, et al. (2015) Enantioselective Synthesis of $\beta$-amino acids: A Review. Med chem 5: 295-309. doi: 10.4172/2161-0444.1000278

109. Saylik D, Campi EM, Donohue AC, Jackson WR, Robinson AJ (2001) A new enantioselective synthesis of $\beta$-amino acids. Tetrahedron : Asymmetry 12 : 657-667.

110. Juhl K, Jørgensen KA (2002) Catalytic asymmetric direct alpha-amination reactions of 2-keto esters: a simple synthetic approach to optically active synbeta-amino-alpha-hydroxy esters.J Am Chem Soc 124: 2420-2421.

111. Balan D, Adolfsson $\mathrm{H}$ (2003) Chiral quinuclidine-based amine catalysts for the asymmetric one-pot, three-component aza-Baylis-Hillman reaction. Tetrahedron Lett 44: 2521-2524.

112. France S, Wack H, Hafez AM, Taggi AE, Witsil DR, et al. (2002) Bifunctional asymmetric catalysis: a tandem nucleophile/Lewis acid promoted synthesis of beta-lactams.Org Lett 4: 1603-1605.

113. Hasegawa A, Naganawa Y, Fushimi M, Ishihara K, Yamamoto $H$ (2006) Design of $\mathrm{Br} \tilde{A}_{3}$ nsted acid-assisted chiral Brønsted acid catalyst bearing a bis(triflyl) methyl group for a Mannich-type reaction.Org Lett 8: 3175-3178.

114. Akiyama T, Saitoh Y, Morita H, Fuchibe K (2005) Enantioselective MannichType Reaction Catalyzed by a Chiral Brønsted Acid Derived from TADDOL. Adv Synth Catal 347: 1523-1526.

115. Kobbelgaard S, Brandes S, Jorgensen KA (2008) Asymmetric organocatalyzed [1,3]-sigmatropic rearrangements. Chem Eur J 14: 1464-147.

116. Seayad J, Patra PK, Zhang Y, Ying JY (2008) Organocatalytic synthesis of $\mathrm{N}$-Phenylisoxazolidin-5-ones and a one-pot synthesis of beta-amino acid esters.Org Lett 10: 953-956.

117. Müller R, Goesmann H, Waldmann H (1999) N,N-Phthaloylamino Acids as Chiral Auxiliaries in Asymmetric Mannich-Type Reactions. Angew Chem Int Ed 38: 184-187.
118. Marcotte S, Pannecoucke X, Feasson C, Quirion JC (1999) Enantioselective Synthesis of $\alpha, \alpha$-Difluoro- $\beta$-amino Acid and 3,3-Difluoroazetidin-2-one via the Reformatsky-Type Reaction of Ethyl Bromodifluoroacetate with Chiral 1,3-Oxazolidines. J Org Chem 64: 8461-8464

119. Baldoli C, Buttero PD, Licandro E, Papagni A (1996) Tricarbonyl(n6arene) Chromium(0) complexes as chiral auxiliaries: Asymmetric synthesis of $\beta$-aminoesters and $\beta$-lactams by Reformatsky condensation. Tetrahedron 52 : 4849-4856.

120.Shankar BB, Kirkup MP, McCombie SW, Clader JW, Ganguly AK (1996) Synthesis of an optically pure 3-unsubstituted $\beta$-lactam using an asymmetric Reformatsky reaction and its conversion to cholesterol absorption inhibitors. Tetrahedron Lett 37: 4095-4098.

121. Fujieda H, Kanai M, Kambara T, lida A, Tomioka KJ (1997) A Ternary Complex Reagent for an Asymmetric Reaction of Lithium Ester Enolates with Imines. Am Chem Soc 119: 2060-2061.

122. Tomioka K, Fujieda H, Hayashi S, Hussein MA, Kambara T, et al. (1999) Catalytic asymmetric reaction of lithium ester enolates with imines. Chem Commun 715-716.

123. Soloshonok VA, Kukhar VP (1996) Biomimetic base-catalyzed [1,3]-proton shift reaction. A practical synthesis of $\beta$-fluoroalkyl- $\beta$-amino acids. Tetrahedron 52: 6953-6964.

124. Soloshonok VA, Ono T, Soloshonok IV (1997) Enantioselective Biomimetic Transamination of $\beta$-Keto carboxylic Acid Derivatives. An Efficient Asymmetric Synthesis of $\beta$-(Fluoroalkyl) $\beta$-Amino Acids. J Org Chem 62: 7538-7539.

125. Soloshonok VA, Soloshonok IV, Kukhar VP, Svedas VK (1998) Biomimetic Transamination of a-Alkyl $\beta$-Keto Carboxylic Esters. Chemoenzymatic Approach to the Stereochemically Defined a-Alkyl $\beta$-Fluoroalkyl $\beta$-Amino Acids. J Org Chem 63: 1878-1884. 